\title{
Women, Water, and Well-being: Gendered Experiences of Household Water Contamination in Parkersburg, West Virginia
}

\author{
Emily Brooke Tingler \\ West Virginia University, ebtingler@mix.wvu.edu
}

Follow this and additional works at: https://researchrepository.wvu.edu/etd

Part of the Human Geography Commons, and the Nature and Society Relations Commons

\section{Recommended Citation}

Tingler, Emily Brooke, "Women, Water, and Well-being: Gendered Experiences of Household Water Contamination in Parkersburg, West Virginia" (2021). Graduate Theses, Dissertations, and Problem Reports. 8285.

https://researchrepository.wvu.edu/etd/8285

This Thesis is protected by copyright and/or related rights. It has been brought to you by the The Research Repository @ WVU with permission from the rights-holder(s). You are free to use this Thesis in any way that is permitted by the copyright and related rights legislation that applies to your use. For other uses you must obtain permission from the rights-holder(s) directly, unless additional rights are indicated by a Creative Commons license in the record and/ or on the work itself. This Thesis has been accepted for inclusion in WVU Graduate Theses, Dissertations, and Problem Reports collection by an authorized administrator of The Research Repository @ WVU. For more information, please contact researchrepository@mail.wvu.edu. 
Women, Water, and Well-being:

Gendered Experiences of Household Water Contamination in Parkersburg, West Virginia

\author{
Emily Tingler \\ Thesis submitted to the Eberly College of Arts and Sciences \\ at West Virginia University \\ in partial fulfillment of the requirements \\ for the degree of \\ Master of Arts in \\ Geography \\ Jamie Shinn, Ph.D., Chair \\ Daniel Renfrew, Ph.D. \\ Bradley Wilson, Ph.D. \\ Department of Geology \& Geography
}

Morgantown, West Virginia

2021

Keywords: water contamination, gender, risk, power, health, environmental reproductive justice, political ecology, feminist geography, West Virginia, DuPont

\title{
Copyright 2021 Emily Tingler
}




\begin{abstract}
Women, Water, and Well-being:

Gendered Experiences of Household Water Contamination in Parkersburg, West Virginia

Emily Tingler
\end{abstract}

DuPont Washington Works chemical plant knowingly pumped hundreds of thousands of pounds of toxic C8 waste into local waterways, water tables, and landfills for over 40 years, contaminating the drinking water for more than 100,000 residents in and around Parkersburg, West Virginia. Drawing on feminist political ecology and the political ecology of water with literature on perceptions of risk in contaminated communities, environmental reproductive justice, modern water, and hydrosocial waterscapes, I examine, through a qualitative case study, the lived experiences of women who have an intimate understanding of C8 water contamination from the DuPont Washington Works chemical plant. Specifically, I explore how these women conceptualize risk and contamination due to polluted water and the impacts of this risk on their bodies and overall well-being, as well as women's hope for the future of water quality in Parkersburg. There is growing literature on the lived experience of PFAS or Per- and polyfluoroalkyl substances exposure, which includes C8 or PFOA, that aims to uncover the often silenced stories of those whose household water security is impacted by these chemicals. This thesis reveals that women experience specific gendered consequences as a result of $\mathrm{C} 8$ exposure that includes unequal power relations, altered perceptions of water and risk, complex feelings of hope, and severe reproductive and autoimmune health impacts. I contribute to bridging two areas of literature - feminist political ecology and environmental reproductive justice - in an attempt to create a holistic understanding of women's everyday experiences of water contamination and highlight the direct relationship between unequal power relations and negative impacts on women's reproductive health. 


\section{Acknowledgements}

I wish to express my sincere gratitude to Dr. Jamie Shinn for her unwavering support throughout this entire process. Without her, I am not sure I would be where I am today. Her brilliance and empathy carried me to this point, and for that I will be forever grateful. Thank you to Dr. Bradley Wilson and Dr. Daniel Renfrew for their mentorship, critical guidance, and thoughtful feedback. Thank you to Dr. Martina Caretta, Dr. Jonathan Hall, and Dr. Karen Culcasi for being wonderful professors who, through a global pandemic, shared knowledge and remained engaged with their students. Thank you to Valerie Slone for always showing up for me when I needed a friend to laugh, cry, and eat pizza with. Thank you to Valentina Muraleedharan, Brandon Rothrock, and Amanda Marple for their constant encouragement and for their listening ear. Thank you to Tatum Storey, Lindsey Burgess, and Allie Moses for keeping me sane and for showing compassion when times were hard. Lastly, I would like to thank the 18 women who shared with me their personal stories of vulnerability and strength. I am forever inspired by their words. 


\section{Table of Contents}

CHAPTER 1: INTRODUCTION, RESEARCH AIM AND QUESTIONS, AND BACKGROUND ...................................



1.2 RESEARCH AIM AND QUESTIONS..............................................................................................................................................2

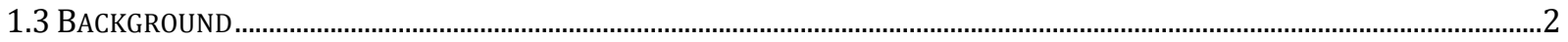

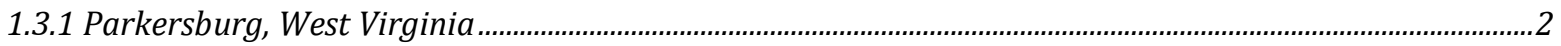

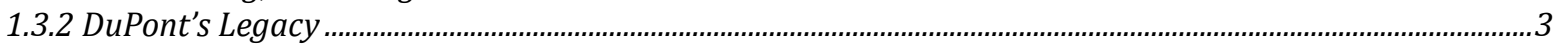

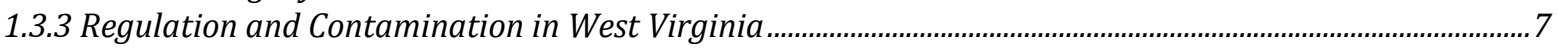

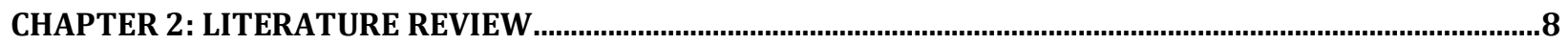

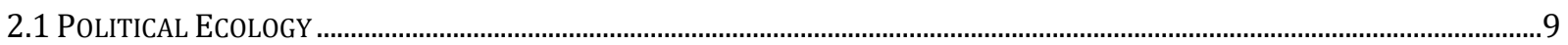

2.1.1 Living with Risk in Contaminated Environments ...................................................................................11

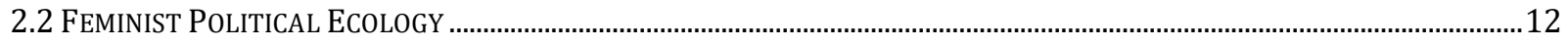

2.2.1 Environmental Reproductive Justice ……....................................................................................................... 14

2.3 THE POLITICAL ECOLOGY OF WATER ……..........................................................................................................................16

2.3.1 Modern Water ...............................................................................................................................................................

2.3.2 Hydrosocial Waterscapes.............................................................................................................................. 19



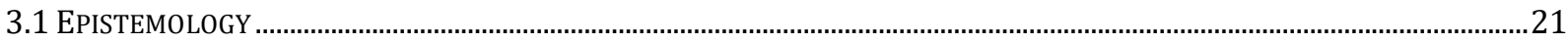

3.2 PERSONAL BACKGROUND AND INTEREST ....................................................................................................................................23

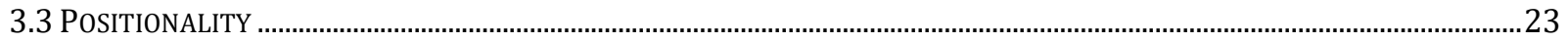

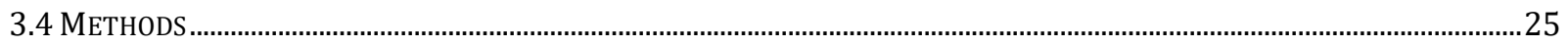

3.4.1 Case Study: Parkersburg, West Virginia …............................................................................................... 26

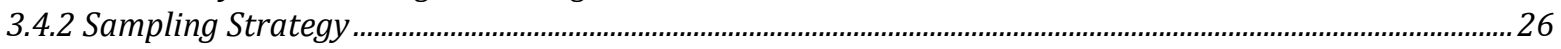

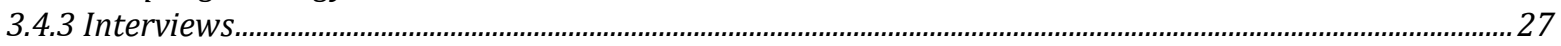

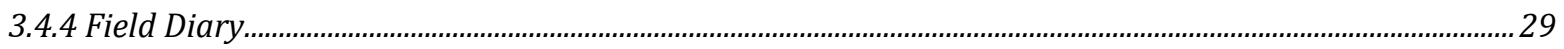

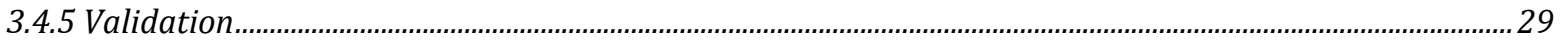



3.4.7 Future Dissemination ........................................................................................................................................... 32

CHAPTER 4: FINDINGS: EXPERIENCES OF WATER CONTAMINATION, RISK, POWER, HEALTH, AND

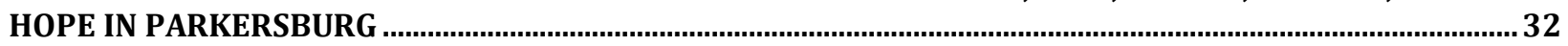

4.1 DisRupting the Myth of Modern Water through Examination of the PARKERSBURG WatersCaPe ...................32



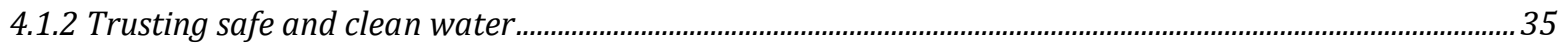

4.1.3 Distrust of water quality reports ……................................................................................................................... 37





4.4 ENVIRONMENTAL REPRODUCTIVE JUSTICE AND WOMEN'S HEALTH IN PARKERSBURG ........................................................50

4.5 HOPE IN THE "CHEMICAL VALLEY”.......................................................................................................................................

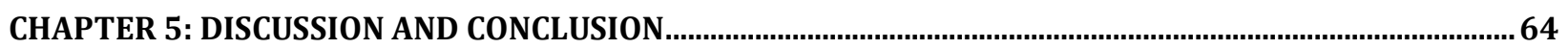

5.1 The Political Ecology of C8 CONTAMination In PARKERSBURG, WV...............................................................................70

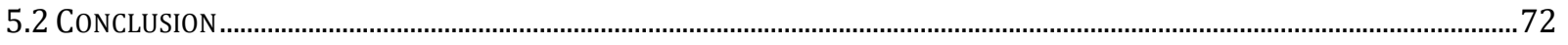

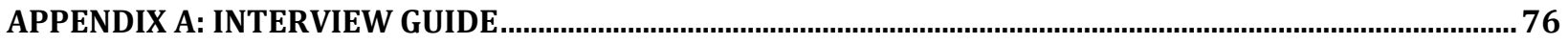

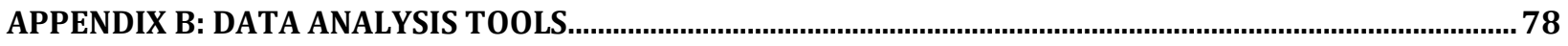

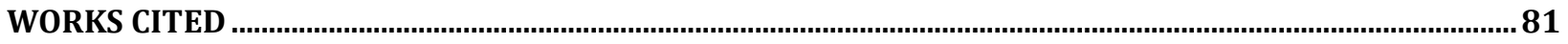




\section{List of Figures}

Figure 1: Map of all Chemical and Polymer Manufacturers in West Virginia..........................................................................

Figure 2: DuPont Washington Works Plant in relation to Parkersburg, WV and surrounding areas..................................

Figure 3: A letter currently posted on the Lubeck PSD website to customers explaining that their tap water might

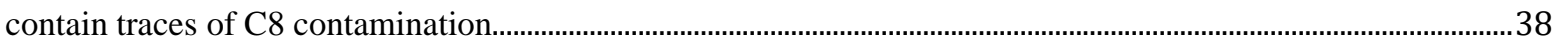

Figure 4: DuPont's Happy Pan Advertisement from the 1960s.........................................................................................59

Figure 5: Screenshot from Teflon II/Silverstone/Suprex No-Stick Seal 'Don't Get Stuck' Commercial..........................59 


\section{Chapter 1: Introduction, Research Aim and Questions, and Background}

\subsection{Introduction}

From 1951 to 2015, the DuPont Washington Works chemical plant knowingly contaminated local water sources in and around Parkersburg, West Virginia with the chemical $\mathrm{C} 8$, through dumping toxic waste into local landfills, creeks, and rivers. C8 infiltrated the local water table, which provided drinking water for more than 100,000 people in the Parkersburg area. Throughout the course of the controversy, DuPont worked with state institutions to cover up their wrong-doings and conceal evidence that proved C8's harm to humans, which they had known about for over 40 years. After evidence came to light, a class-action lawsuit was launched against DuPont. However, since the 2001 lawsuit, there has been little resistance aside from a few outspoken activists and the formation of a small, currently inactive community-based organization called Keep Your Promises.

The class-action lawsuit filed against DuPont included over 80,000 participants. The plaintiffs won the class-action and with the money from the settlement, they launched a health study to test locals for $\mathrm{C} 8$ contamination and correlations to disease. The study found a link between $\mathrm{C} 8$ contamination and six medical conditions, including two types of cancer and birth defects. After harsh criticism, Dupont halted production of $\mathrm{C} 8$, changed the name of the Washington Works plant to Chemours, and began producing a new and supposedly safer substance called GenX.

This research project investigated gendered experiences of and relations to $\mathrm{C} 8$ water contamination for women living in and around Parkersburg, WV. To accomplish this, I conducted a qualitative analysis that centered the voices of 18 women from the Parkersburg area. My research is influenced by feminist methodologies as I examined women's understandings of risk from water contamination caused by the DuPont Washington Works chemical plant, how these risks impact women's bodies and overall well-being, and women's hope for the future of water quality in Parkersburg. I contribute to and draw from several distinct areas of literature including political ecology, feminist political ecology, environmental reproductive justice, and the political ecology of water. 


\subsection{Research Aim and Questions}

The aim of this research was to explore the lived experiences of women impacted by C8 water contamination in and around Parkersburg, WV. Specifically, I investigated how these women conceptualize risk and contamination due to polluted water and the impacts of this risk on their bodies and overall well-being, as well as women's hope for the future of water quality in Parkersburg. For the purposes of my research, I used Kearns and Andrews' (2010, 309) definition of well-being that states, "well-being is an experienced or emplaced state of being, in terms of healthiness and happiness." Well-being must be understood in relation to place, as one's state of well-being is affected by environmental and spatial contexts of everyday life (Kearns and Andrews 2010). Moreover, studying well-being means to explore one's physical, social, economic, and emotional comfort or discomfort, as a way to understand one's quality of life. There are three overarching research questions:

1) What are women's understandings of risk associated with household water contamination caused by the Dupont Washington Works plant in Parkersburg, West Virginia?

2) How do these understandings and experiences of risk impact women's bodies and overall well-being?

3) What are women's hopes for the future of water quality in Parkersburg?

\subsection{Background}

\subsubsection{Parkersburg, West Virginia}

Resting at the convergence of the Ohio and Little Kanawha rivers is Parkersburg, West Virginia. Parkersburg is home to around 30,000 people, with the population steadily declining since the 1970s (U.S. Census Bureau 2019). Parkersburg is a predominantly white city, with 94.3\% of residents identifying as "white alone," $3.1 \%$ as "Black or African American alone," and $1.7 \%$ as "two or more races" (U.S. Census Bureau 2019). Of its residents, $25.2 \%$ live in poverty, which is much higher than the WV state average at 16\%. In Wood County, where Parkersburg is located, $4.1 \%$ are unemployed (U.S. Census Bureau 2019).

West Virginia's second most profitable industry is chemical manufacturing, with $\$ 8,476,074,000$ in revenue in 2018 and allocating over $\$ 714$ million in local wages (U.S. Census Bureau 2019) (Figure 1). Wood County is home to four of these major chemical plants and many 
people in the area have grown loyal to the steady and gainful employment. DuPont, now housed in Chemours Inc., employs over 700 people within its 170 acre plant (Develop Wood County 2020).
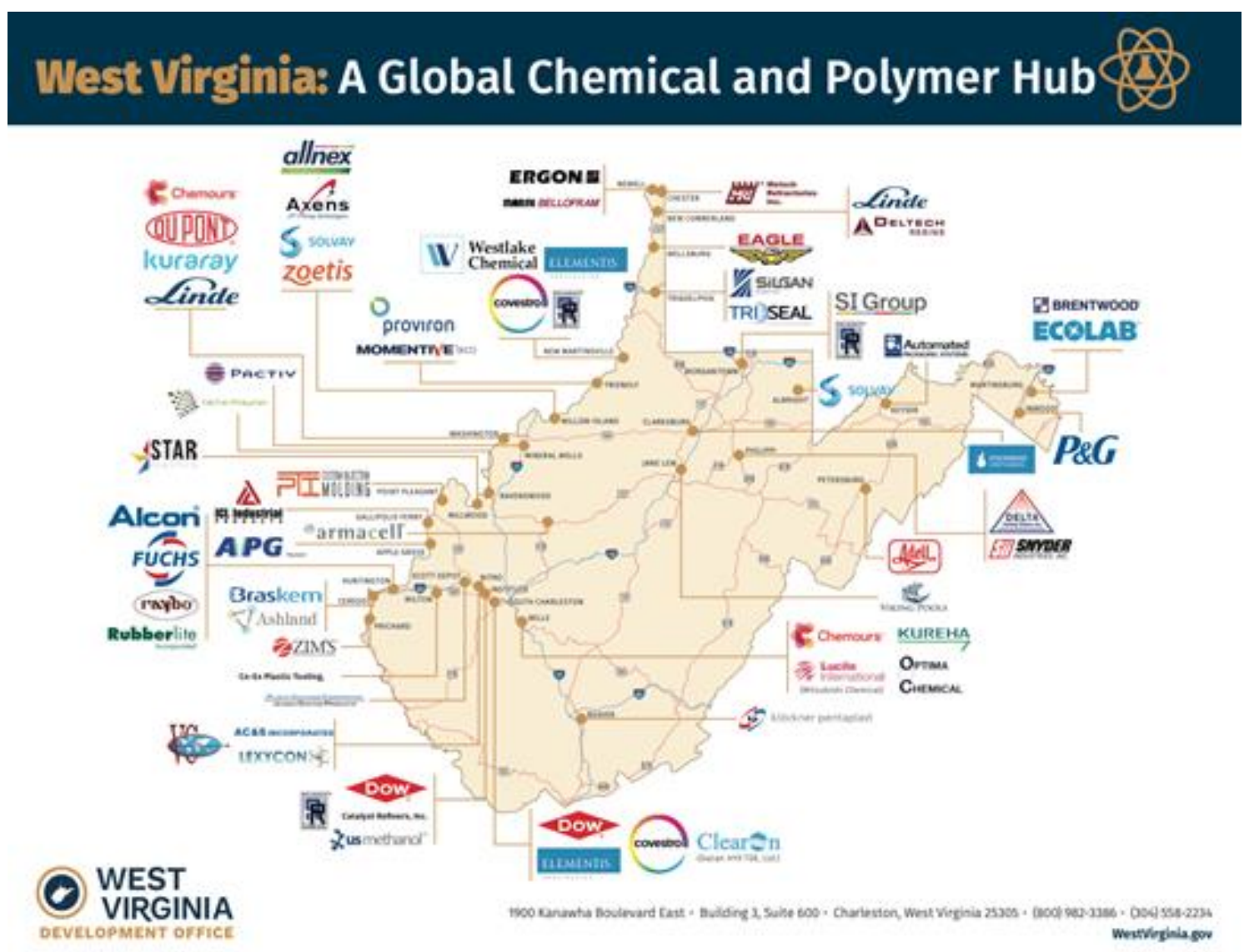

Figure 1: Map of all Chemical and Polymer Manufacturers in West Virginia. Source: https://westvirginia.gov/industries/chemical-polymer/

\subsubsection{DuPont's Legacy}

DuPont's Washington Works chemical plant is a chemical company located in Wood County, West Virginia, just on the outskirts of Parkersburg, WV (Figure 2). In 1951, DuPont started purchasing Perfluorooctanoic acid (PFOA), colloquially known as C8, from 3M in order to manufacture Teflon (Rich 2016). Teflon is a chemical coating that is typically used as a nonstick coating for cookware and is one of the main products produced by DuPont's Washington Works. After DuPont purchased C8, 3M sent along their recommended methods of disposal that included either incineration or sending the C8 waste to a chemical-waste facility. It was made clear to DuPont by $3 \mathrm{M}$ that $\mathrm{C} 8$ should never be flushed into groundwater, bodies of water, or 
sewers (Rich 2016). This was recommended because PFOA persists in the environment, including human bodies, and will never break down (CDC 2017).

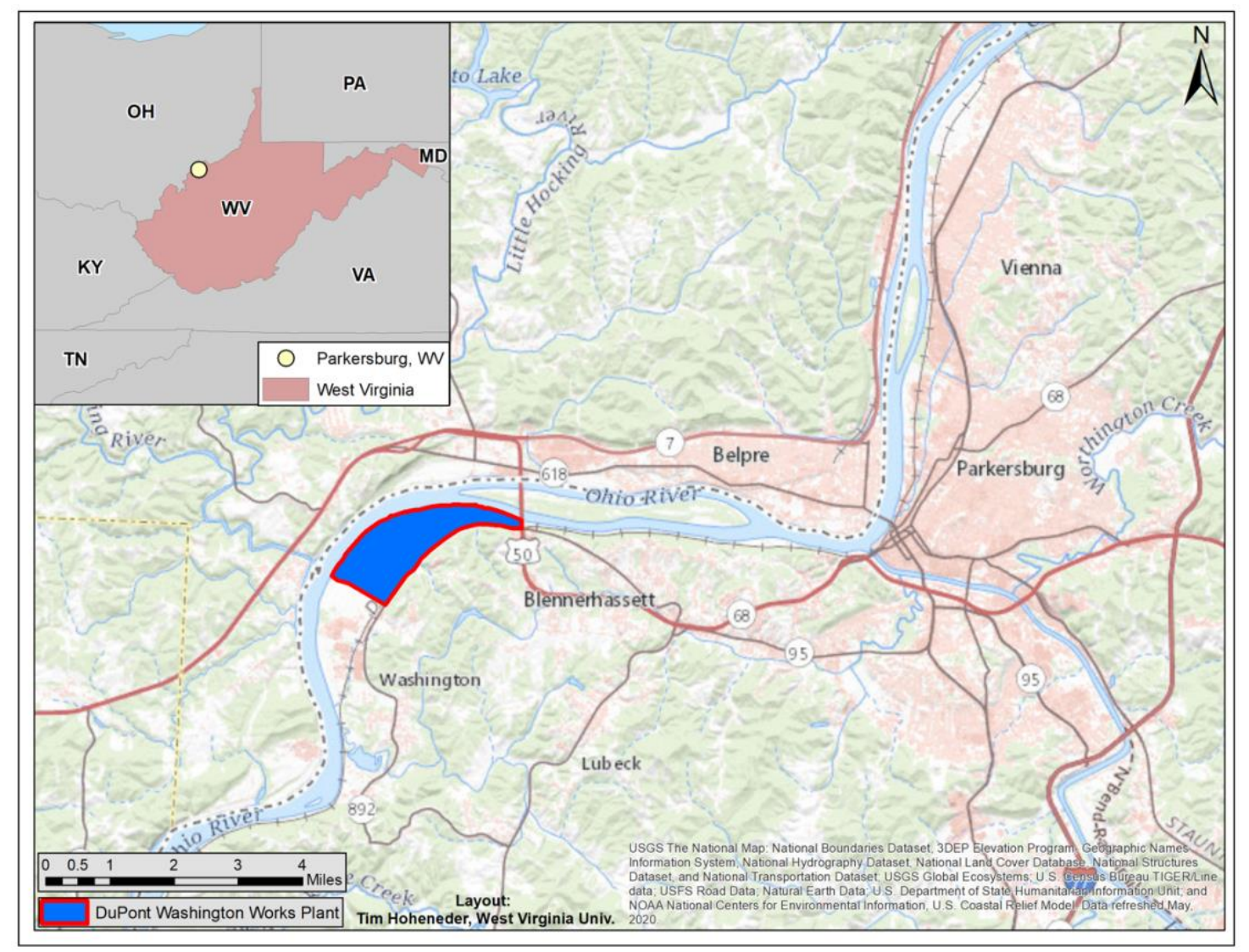

Figure 2: DuPont Washington Works Plant in relation to Parkersburg, WV and surrounding areas. Source: Tim Hoheneder

In the 1980s, DuPont contacted one of its laborers, Jim Tennant, and asked to buy a plot of land on his 700-acre farm located just outside of Parkersburg to use as a landfill for waste from the plant (Rich 2016). The Tennant family accepted, as they were in desperate need of money and DuPont stated they would only dispose of non-toxic material (Blake 2015). In the late 1990s, the Tennant family called Rob Bilott, a lawyer who frequented Parkersburg as a child and who had familial ties to the Tennant's neighbors. By the time the Tennant's called Bilott, they were experiencing various issues related to environmental degradation of their land and resources. The creek just beyond the new landfill was black and foamy, deer carcasses were scattered around the property, and their cattle had been experiencing disease and death (Blake 2015). 
Rob Bilott agreed to take on the case and what followed was the uncovering of decades of coverups and misinformation perpetuated by DuPont. Bilott received years' worth of reports and documents pertaining to hazardous substances used at the DuPont Washington Works plant. One of these documents contained references to PFOA, but this term was not found on any of the other documents received. Bilott requested from the court that DuPont release all documentation related to PFOA, and after much protest from DuPont, the court granted this request (Rich 2016).

Through these documents, Bilott discovered that DuPont had been pumping PFOA waste into local waterways and water tables for over 40 years. The documents also contained evidence that DuPont had been conducting studies that determined PFOA caused detrimental health effects in animals, that PFOA was present in the blood of Dupont's workers, and that it was present in the local water table (Rich 2016). Over the years, DuPont pumped hundreds of thousands of pounds of PFOA powder through pipes that led to the Ohio River (Rich 2016). Reports showed that the company dumped 7,100 tons of PFOA sludge into open pits on the Washington Works property that seeped into the ground and into the water table that supplied drinking water to over 100,000 people living in the Parkersburg region (Rich 2016). Some of the sludge from these pits was moved to the landfill they had purchased from the Tennants.

Bilott also discovered that in 1981, both DuPont and 3M conducted experiments on lab rats who had ingested PFOA. They found that ingestion of the substance caused birth defects and testicular and liver cancer (Rich 2016). Following this revelation, DuPont studied the children of pregnant employees in the Teflon division of the plant. Out of seven births, two had extreme eye defects (Rich 2016). This information was never made public by DuPont. Finally, in 1991, DuPont determined that the internal safety limit for PFOA concentration in drinking water was one part per billion (Rich 2016). In the same year, they discovered that the water in a nearby community contained PFOA levels of over three times the internal safety limit. This information was also not released to the public.

After the discovery of these reports, Bilott began preparing a class-action lawsuit against Dupont on behalf of those impacted by contaminated drinking water. When DuPont heard of this impending lawsuit, they formed a team that consisted of members from the West Virginia Department of Environmental Protection and DuPont. They reevaluated the internal limit and announced a new limit of 150 parts per billion, 150 times higher than DuPont's original internal safety guidelines (Blake 2015, Rich 2016). This was contradictory to other toxicology reports 
that stated the safety limit as 0.2 parts per billion (Rich 2016). Later it was discovered that the those who determined the new safety limit and regulations had been employed by DuPont in the past.

Rob Bilott launched the class-action lawsuit in 2001. By 2004, the lawsuit involved more than 80,000 plaintiffs and DuPont settled for approximately $\$ 374$ million. Included in the settlement was a promise to install filtration systems in contaminated districts, as well as $\$ 70$ million dedicated to a health and education project that was to benefit the impacted community (Rich 2016). It also funded a $\$ 30$ million health study to evaluate the effects of $\mathrm{C} 8$ on the population surrounding the chemical plant. Three epidemiologists were appointed by the Circuit County Clerk of Wood County to form the C8 Science Panel (Nicole 2013). The panel collected data from community residents from 2005 to 2011 . The $\$ 70$ million set aside for the health and education project was ultimately used to pay community members $\$ 400$ for their participation in the C8 science panel study. Each person who participated received $\$ 400$ dollars as compensation for their time. Approximately 33,000 individuals volunteered for the study, including almost 5,000 DuPont workers (Nicole 2013). The study showed an association between PFOA exposure and six health outcomes: kidney cancer, testicular cancer, ulcerative colitis, thyroid disease, hypercholesterolemia, and pregnancy-induced hypertension (Nicole 2013). As of October 2016, over 3,500 plaintiffs have filed personal injury lawsuits against DuPont as a result of the study (Rich 2016).

98\% of Americans now have traces of PFOA in their blood (CDC 2017). Since the classaction lawsuit, DuPont Washington Works changed their name to Chemours and stopped producing C8 in their Washington Works plant. In 2009, Chemours began producing a closely related substance called Perfluorohexanoic acid, colloquially known as C6 or GenX, to act as a "sustainable replacement" to C8 (DuPont 2010). GenX can be used to make non-stick coating without the use of PFOA. In November of 2018, the United States Environmental Protection Agency noted that GenX can now be found in surface water, groundwater, drinking water, and rainwater in areas surrounding the Chemours chemical plant in Parkersburg, West Virginia and in Fayetteville, North Carolina (EPA 2018). Studies conducted on animals exposed orally to GenX show that GenX has adverse health effects in the kidney, blood, immune system, developing fetus, and the liver (EPA 2018). In 2018, the EPA said in a violation notice that 
Chemours failed to notify the EPA when they learned that GenX had contaminated water wells and properties near Parkersburg (Tatar and Baucher 2018).

\subsubsection{Regulation and Contamination in West Virginia}

West Virginia is no stranger to water contamination. With a deep history of extractive and chemical industries, many West Virginian streams, rivers, and water tables have experienced contamination. For instance, in 2014, 10,000 gallons of chemicals, mainly 4-methylcyclohexane methanol (MCHM) used to process coal, spilled into the Elk River in Charleston, WV. This river provides drinking water for nearly 300,000 residents of the Charleston area (U.S. National Toxicity Program 2016). In the five days following the spill, residents were issued a "do-notuse" advisory and were advised not to drink, cook with, or bathe using municipal tap water.

This event, along with C8 contamination in Parkersburg, are just two examples of the many chemical pollutants that threaten West Virginia's waterways. In fact, a new study released in 2019 by three environmental groups found that more than half of West Virginia counties rank among the worst in the nation for violations of a federal law that protects the quality of drinking water in the US (Allen 2019). West Virginia rarely sees any bills in the legislature regarding water quality, infrastructure, and protection with many water quality rules not being updated since the 1980s (Coyne 2019). In 2018, WV legislature decided not to adopt amendments regulating 60 pollutants, despite recommendation from the WV Department of Environmental Protection based on findings by the US Environmental Protection Agency (Coyne 2019). A common sentiment shared by WV Republican representatives is that deregulation is needed to attract and retain businesses in West Virginia, therefore they reject most calls for increased regulation.

Among the thousands of chemicals that have evaded regulation in the US are poly or perfluoroalkyl compounds (PFAS), despite the inherent risk to human health. For decades, chemical industries claimed PFAS as safe and found agreement among federal officials throughout the United States (Bilott 2019). However, in February 2021, the US EPA announced a new set of actions aimed at addressing PFAS in US drinking water with the EPA stating, "The Biden-Harris administration is committed to addressing PFAS in the nation's drinking water and will build on these actions by advancing science and using the agency's authorities to protect public health and the environment" (EPA 2021). The aforementioned actions include 
reproposing a rule that will collect new data on PFAS contaminated drinking water and later issuing a final regulatory determination for PFOA or C8 under the 2021 Safe Drinking Water Act (EPA 2021). This is certainly a step in the right direction after much rejection from the Trump Administration.

Because PFOA has gone largely unregulated, citizens in Parkersburg have experienced longitudinal contamination. There are numerous medical studies on the effects of PFAS exposure and growing research on lived experience of those impacted by PFAS contamination. A focus on the everyday lived realities of exposure, as highlighted in this thesis, can contribute to the formation of stronger regulatory standards that include not just techno-scientific standards, but also lived experience.

\section{Chapter 2: Literature Review}

This research is theoretically grounded most broadly in political ecology (PE), with more specific contributions and connections to feminist political ecology (FPE) and the political ecology of water. Although the nature of political ecology is expansive, scholarship in the field is defined by the contextualization of environmental phenomena with attention to broader social, political, and economic conditions. Political ecology is a useful conceptual framework for my research because it enabled my investigation of gendered understandings of water contamination and the gendered costs and benefits associated with environmental pollution. I contextualized women's understandings of water contamination through my investigation of the broader power dynamics that operate within the Parkersburg region, specifically through my examination of the unequal power relationships between DuPont and women impacted by water contamination.

Within the overarching field of political ecology, I specifically draw from and contribute to work in feminist political ecology (FPE) and the political ecology of water. In relation to FPE, I use several concepts to situate my findings, including a focus on the household scale, gendered environmental rights and responsibilities, and embodied relationships to contaminated water. In this section, I argue that there is an important connection to be made between FPE and the emerging field of Environmental Reproductive Justice (ERJ). A major contribution of my research is bridging these two areas of literature, which I accomplish by using FPE, as it tends to power relations, and how these relations shape reproductive health in Parkersburg. 
Regarding the political ecology of water, I use concepts of modern water and waterscapes to elucidate my analysis of risk, power, hope, and health in the Parkersburg region. My research is an example of a hydrosocial waterscape that dispels the myth of modern water by illuminating the realities of water contamination and its impact on women's bodies and wellbeing.

\subsection{Political Ecology}

Political ecologists critically analyze the economic, social, and political factors that shape environmental phenomena with an attempt to uncover the power dynamics and relationships that move through environmental systems and transformations. The first scholars to use the term "political ecology" were writer Alexander Cockburn and anthropologist Eric Wolf in the 1970s. They coined the term in consideration of access and control over natural resources in "third world" countries (Wolf 1972; Peet and Watts 1996). However, Land Degradation and Society by Blaikie and Brookefield, published in 1987, is considered to be the first foundational text in the field. In the book, Blaikie and Brookefield gave one of the first definitions of political ecology. They wrote, "The phrase 'political ecology' combines the concerns of ecology and a broadly defined political economy. Together this encompasses the constantly shifting dialectic between society and land-based resources, and within classes and groups within society itself (Blaikie and Brookefield 1987)." They highlighted this dialectic relationship between society and the nonhuman environment by developing a multi-scalar analysis of environmental degradation from a political economy perspective.

Their book emphasized the role of the biological and physical characteristics of particular environments in creating management tasks for land users within the context of broader social and political economic conditions (Blaikie and Brookfield 1987). Some scholars argued that their work was too focused on the physicality of the land and environmental change and not enough on the political economic interactions between local communities and global forces. By the late 1990s, political ecology shifted to a poststructuralist approach and began putting more emphasis on the political. During this time, Peet and Watts published Liberation Ecologies, where they created broad themes including the concept of marginality, the pressure of production on resources, and the inadequate representation of environmental data of historical depth (Peet and Watts 1996). 
Directly following Liberation Ecologies, Bryant and Bailey released Third World Political Ecology. This text was the first major attempt to explain connections between development and environmental problems that affect parts of Asia, Africa, and Latin America. Bryant and Bailey's book highlighted three fundamental assumptions of political ecology at the time that solidified the understanding of a "politicized environment": that costs and benefits associated with environmental change are distributed unequally, this unequal environmental distribution inevitably reinforces or reduces existing social and economic inequalities, and the unequal distribution of costs and benefits and the reinforcing or reducing of pre-existing inequalities hold political implications in terms of the altered power relationships that are produced (Bryant and Bailey 1997).

These noteworthy developments in political ecology were instrumental in creating the robust field that exists today. In 2004 (and in a second edition in 2011), Paul Robbins detailed the common themes, questions, and debates that typically occur in the practice of PE in the first edition of his book, Political Ecology: A Critical Introduction. He highlighted the transformation of the field that went from heavy focus on environmental degradation to human influences on the production of social-environments and how they are affected by humans and non-humans alike. Robbins argued that the five central theses of PE research are as follows: degradation and marginalization, conservation and control, environmental conflict and exclusion, environmental objects and identity, and political objects and actors (Robbins 2011).

With degradation and marginalization, scholars try to explain environmental conditions and the reasons for their change, usually shifting blame from marginalized people to a larger political and economic context. The conservation and control narrative discusses failures of conservation outcomes and shows how some environmental conservation efforts may have harmful effects on its surroundings. Environmental conflict and exclusion explains unequal access to the environment and natural resources and conflicts over exclusion from these resources. It explains that conflicts are underscored by larger gendered, classed, and race struggles. Environmental subjects and identity works to explain how identities of people and social groups and problems associated with them are linked to basic issues of livelihood and environmental activity. Lastly, political objects and actors explain the socio-political conditions that are created by the relationship between political and economic systems and non-human actors. These categories help to better define the parameters of what can be considered "political 
ecology." Political ecology is a useful conceptual framework for my research because it enabled my investigation of gendered understandings of water contamination and the gendered costs and benefits associated with environmental change and pollution.

\subsubsection{Living with Risk in Contaminated Environments}

Environmental risks, including natural hazards and pollution, were traditionally measured using quantitative, technical risk assessment standards (Wakefield et al. 2001). However by the late 1990s, human geographers and political ecologists increasingly rejected these approaches and instead turned to cultural, sociological, and qualitative approaches to studying risk, as they determined that risk is a socially and culturally constructed phenomenon (Bennett 1999; Baxter et al. 1999; Wakefield et al. 2001).

The turn to this qualitative approach coincided with Ulrich Beck's famous claim that we increasingly live in a "risk society" (Bennett 1999; Beck 1992). Beck defined risk as 'a systematic way of dealing with hazards and insecurities induced and introduced by modernization itself" (Beck 1992, 21). He argued that the risks in the late $20^{\text {th }}$ century and beyond are occurring at a greater scale and with more uncertainty, compared to the preceding industrial society (Bennett 1999; Beck 1992). These risks included nuclear threat, pollution from chemical companies, and environmental destruction due to an increasingly industrialized society (Bennett 1999; Beck 1992). Prior to our modern risk society, Beck argued that risks were more discrete and predictable (Beck 1992). In the modern era, industrial risks often go unseen, as things like bioaccumulative chemical contamination and large-scale climate change are hard to bound in space or time (Beck 1992).

Definitions of risks and hazards are often problematized, as some scholars find a disconnect between lived experience of risk and official evaluations of risk (Brullel and Pellow 2006; Checker 2007). Research on lived experience of risk is important, as it becomes a valuable tool in developing less biased and more accurate assessments of risk (Checker 2007). One way to develop more comprehensive and grounded assessments of risk is by combining public and scientific expertise when developing risk assessments (Checker 2007).

In the past two decades, there has been more spatially cognizant research on how different communities perceive, categorize, and prioritize risk (Checker 2007). Scholars across disciplines have studied perceptions of risk in contaminated communities (Auyero and Swistun 
2009; Tartaglia et al. 2018; Sullivan and Young 2020). For example, Auyero and Swistun (2009) observed many residents in an Argentine shantytown that had low perceptions of risk even though they lived in an area with known hazardous pollution, which they attributed to strong attachment to place. Tartaglia et al. (2018) found that residents living in a contaminated area near an Italian steel plant recognized significant risk from environmental pollution, which led to a decreased sense of and attachment to place (Tartaglia et al. 2018).

Other studies of hazardous communities have found that residents of contaminated areas are unwilling to move despite obvious risk due to their sense of place (Preston et al. 1983; Bonaiuto et al. 2016; Sullivan and Young 2020). These studies reveal that there is a tendency for those with a strong sense of place to refuse to proactively and retroactively cope with and respond to environmental threats (Bonaiuto et al. 2016).

Langford (2002) identified three types of environmental threat response that can be seen within individuals, which Sullivan and Young (2020) have interpreted as apathy, denial, and scapegoating. Apathy, in this sense, refers to the upkeep of calmness in the face of significant risk by claiming an inability to respond or a lack of knowledge (Sullivan and Young 2020). Denial refers to the minimization of risk and scapegoating refers to one coping through defense strategies that aim to "restore epistemic control" (Sullivan and Young 2020). As discuss below in section 4.2, the categories of denial and apathy are particularly relevant to my work as I investigated women's understandings of (and responses to) risk of C8 contaminated water in Parkersburg, WV.

This research contributes to knowledge of risk perception through a unique gendered analysis of understandings of risk in a community facing contaminated waterways. Including such local perceptions of risk can make visible a contaminant that may go otherwise unnoticed. Thus, my focus on women's everyday lived experience of this risk has the potential to contribute to better, more holistic understandings and assessments of risk for communities impacted by environmental pollution.

\subsection{Feminist Political Ecology}

In the 1990s, "Feminist Political Ecology (FPE) was being heralded as a promising subfield that sought to join feminist and political ecology scholarship 'from the ground up' (Elmhirst 2011)." FPE analyzes everyday dimensions of resource inequalities through examining 
livelihoods, socially and spatially, and how they are produced and reproduced through gender, class, and other social power relations (Elmhirst 2011). In her article titled, "Introducing new feminist political ecologies," Elmhirst described Rocheleau, Thomas-Slayter, and Wangari's 1996 book Feminist Political Ecology: Global Issues and Local Experiences and how it "invited political ecologists to extend their analysis of power to include gendered relations, and to extend their consideration of scales of analysis to include the household, thus complicating arenas of assumed common interest, including 'community' and 'local' (Elmhirst 2011)." Feminist political ecologists believe that to most effectively focus on everyday lived experience, "household" must be viewed as a credible scale.

This idea of "household" as a viable scale came from the concept of a "gendered science of survival" (Rocheleau et al. 1996). These authors argued that case studies that focus on the household scale have the potential to illuminate the intersection of rural local knowledge and "housewives epidemiology." This intersection allows for gendered knowledge of everyday livelihoods to come to the forefront with a particular focus on rural women's voices (Rocheleau et al. 1996).

When discussing broader themes, Rocheleau et al. focused on three key elements: gendered environmental knowledges, gendered environmental rights and responsibilities, and gendered environmental politics and grassroots activism (Elmhirst 2011). "Gendered knowledge" considers this "science of survival," which includes the creation, upkeep, and protection of healthy environments at home, work, and regionally. "Gendered environmental rights and responsibilities" encompasses all spaces that are deemed feminine or masculine and how those genders are held responsible for its care. Lastly, "gendered environmental politics and grassroots activism" describes women's involvement in collective movements in environmental justice and men's lesser involvement in said movements. Typically, women's involvement in grassroots organizing gets overlooked as men hold the seats in such groups, but women's care and everyday experiences in these organizations are what hold them together (Elmhirst 2011).

Furthermore, scholars in FPE have studied the gender subjectivities that emerge in connection with environmental degradation and natural resource control and access. Sultana (2009) argued that gendered relations and subjectivities are produced through the ways in which people experience and relate to natural resources, including water. She explained that struggles over water or experiences of water contamination inflect gendered identities and sense of self, 
producing and reproducing gendered norms and practices (Sultana 2009). Further, she argued that one may examine embodied subjectivities, specifically feminine subjectivity in the body, in order to understand one's relationship with water (Sultana 2009). For example, experience with water contamination and the materiality of water can influence one's embodied construction of gender, their bodily experiences, and how they interact with their environment (Sultana 2009). Studying embodied consequences of contaminated water through an FPE framework enables scholars to reconceptualize water inequality to fully include inequalities associated with social and spatial differences and their lived, everyday consequences (Truelove 2011).

An FPE framework is useful for analyzing everyday dimensions of water inequality by directly focusing on the ways that daily practices are produced by, and productive of, gender, class, and other social power relations (Truelove 2011). My research was informed by FPE through my examination of water injustices and inequality experienced by women in the Parkersburg region. Truelove's (2011) emphasis on understanding the "everydayness" of water was important in my research, as water injustices in Parkersburg impact the daily lives of women in various ways, including through alternative water procurement strategies or health problems caused by water contamination. Sultana's work on embodied subjectivities and bodily experiences in relation to water helped me think through gendered understandings of risk associated with water contamination and how those risks may impact women's bodies and overall well-being.

My analysis of the risk associated with household water contamination draws from Rocheleau et al.'s conceptualization of the household scale to focus on women's voices and gendered knowledge of livelihoods. Finally, Rocheleau et al.'s concept of gendered environmental knowledges reminded me to center the knowledge of those most vulnerable in society (e.g. women who have experienced water contamination in Parkersburg) and to understand how those marginalized are impacted by environmental change.

\subsubsection{Environmental Reproductive Justice}

Environmental Reproductive Justice (ERJ) scholarship further contributes to understanding the impact of environmental contamination on women's health. Environmental justice is defined as "the fair treatment and meaningful involvement of all people regardless of race, color, national origin, or income, with respect to the development, implementation, and 
enforcement of environmental laws, regulations, and polices" (USEPA). Reproductive justice is defined as "the right to have children, to not have children, and to parent children in a healthy and safe environment" (Price 2010). These two fields converge to create Environmental Reproductive Justice and the intersection of the two highlight the ways that environmental injustices and hazards can lead to reproductive injustices (Liddell and Kington 2021).

ERJ involves expanding reproductive justice to deeply consider the environment's role in shaping women's reproductive health, including reproduction of language, culture, and human beings (Cook 2007; Hoover 2018). ERJ also calls on environmental justice to more explicitly consider how environmental contaminants may impact physical and cultural reproduction (Hoover 2018).

Notably, work in ERJ is often linked to studies in Native American communities facing environmental injustices with connections to reproductive health issues, with ERJ emerging out of Katsi Cook's work on PCB contamination in the Mohawk Nation at Akwesasne (Cook 2007; Hoover 2018). Cook discussed how bioaccumulated contaminants inevitably made their way from mother to child, a sentiment that is echoed within my research, with women in Parkersburg fearing that C8 contamination was passed down in a similar way (Cook 2007).

Medical sociologist, Barbara Gurr, argued that women's bodies experience pollution differently than men's bodies, and that impacts of pollution on women's bodies have particular consequences for the community at large, including related to social, physical, and cultural reproduction (Gurr 2011; Hoover 2018). Others, including environmental sociologist Michael Bell, have argued that one can understand the social and physical impact of environmental pollution on communities at large through the examination of health, adding that there is a perpetual dialog between body and environment, or one's “invironment” (Bell 2009; Gurr 2011; Hoover 2018)

Sandra Steingraber, a biologist who contributes to ERJ literature through her expertise on environmental hazards that threaten reproductive health, argued that "harmful substances have trespassed into the landscape and have also woven themselves...into the fibers of our bodies" (2010, 15), and thus " the environment is not just something else to worry about. It is connected to all the things we already worry about - our children, our health, our homeland"' $(2010,289$; Gurr 2011). The work of Steingraber (2010) and Bell (2009) recognized that the social world, including environmental pollution, has profound impacts on bodies and health. 
My research contributes to and draws from this area of literature through investigation of the impact of water contamination on women's health, especially reproductive health, in Parkersburg, WV. The impact of pollution on women's bodies in Parkersburg is immense, with water contamination greatly affecting social and physical reproduction. Currently, there is little overlap between ERJ and FPE. My analysis of a community whose reproductive capabilities are inhibited by environmental pollution bridges these two literatures. I contribute at the intersection of these literatures by emphasizing the direct relationship between unequal power relations and negative impacts on women's reproductive health. Examining ERJ through an FPE framework can lead to a holistic understanding of women's everyday experience of water contamination which includes conceptualization of risk and bodily experiences of contaminated water, specifically reproductive health impacts, and how these experiences are influenced by social, economic, and political factors within Parkersburg.

\subsection{The Political Ecology of Water}

The political ecology of water is a sub-field that focuses largely on the inclusion of water into broader political economic processes (Loftus 2009). Scholars in political ecology have increasingly considered how water shapes power relations, embodies social relations, and influences the production and reproduction of power in the world (Loftus 2009). Furthermore, scholars working at the intersection of PE and water attempt to reconceptualize human-water relations, from critiquing existing policy and management of water resources towards reimagining a world built on radically different social and natural ties (Budds 2004).

Under the guise of science and scientific methods, state agencies often conclude that water resources are to be managed by the state and are subject to centralized authority (Meehan 2014). However, PE scholars argue that the role of science in managing nature can never be free from the positionalities and biases of the scientific community (Blaikie 1995; Castree 2001; Budds 2014). Therefore, any apolitical approach to the management or development of waterways is problematic and should be questioned. Instead, political ecologists illuminate the social, economic, and political processes that determine water use and access. Such scholars have concluded that water should not be considered as separate from society and can only be understood in the political and economic contexts from which it is produced (Swyngedouw 1999; Budds 2004; Linton 2014). 
To date, most scholarship that focuses on water insecurity has a geographical focus in the global South, with many scholars drawing ties between water, poverty, and lower levels of attainment on human development indices (Meehan et al. 2020; Jepson et al. 2017; Mehta 2014). Recently, however, political ecologists have begun to conduct research on household water insecurity in the global North (Meehan et al. 2020). In work on household water insecurity in the global North, scholars call for a relational approach that centers the systematic processes that reproduce water inequalities and argues that water insecurity is a global condition that exists across multiple scales or levels of development (Meehan et al. 2020). Meehan et al. (2020) argued that household water insecurity is a product of structural and institutionalized power that manifests unevenly through space and time.

In cases of contaminated or unclean water, experts calculate levels of "risk" based on regulatory standards and probability (Meehan et al. 2020). On the other hand, understandings of risk by the general population are often rooted in one's relationship with water and their lived experiences. However, these understandings are formed outside of probabilities or regulations set forth by "objective" science and therefore they are often valued less by the regulatory scientists and water experts who determine water standards (Meehan et al. 2020). At the same time, it is common for people to distrust "expert" approaches to regulation because political and scientific authorities marginalize communities in governance and reporting processes, with regulations often not aligning with self-determined standards (Meehan et al. 2020). Meehan et al. (2020) call for further work that "maps the intersections of expertise, power, and water quality in ways that open new visions of how visible and invisible water contamination can be described, understood, and governed for public health and well-being" in the global North.

\subsubsection{Modern Water}

A common misconception held in Western understandings of household water is that of universal "modern water" (Linton 2010; Meehan et al. 2020). "Modern water" abstracts water from the social, historical, political, and geographic conditions in which it is produced and views water apolitically as an economic or material object meant to be managed and manipulated by humans (Linton 2014; Meehan 2014). The idea of modern water manifests in the global North from practices and discourses associated with scientific models of water creation and management (Meehan et al. 2020). For example, a popularized concept of water is rooted in the 
hydrological cycle, a classic representation of how water functions in the hydrosphere found throughout school textbooks and popular discourse (Linton 2014). This model emphasizes the naturalness of water and represents the cycle as independent from human interference.

There have been several consequences that have come from this particular way of knowing water, including the consolidation of hydrological expertise to the modern state, the identification of water as a "resource" that must be "managed", and the power of the state in managing and controlling this resource (Linton 2014). Modern water rests on the assumption that water and society are distinct from one another, which has allowed humans to believe that water can be manipulated without deep social consequences (Linton 2014). This idea has also led to the conceptualization of infrastructure networks and water services as uniformly distributed services that are accessible to people equally across broad regions (Graham and Marvin 2001; Meehan et al. 2020). This misconception is often refuted by political ecologists, as lived experiences shed light on the social, cultural, and political relations formed between water users and water itself (Swyngedouw 1999; Budds 2014; Linton 2014; Kooy 2014, McCulligh et al. 2020) Hydrosocial hybrids, or instances of water embedded in social relations, are obvious and there are myriad contradictions that dispel the notion of modern water including the pervasiveness of water contamination, unequal access to adequate water, the regulation and exploitation of water systems, and societal effects of large dams (Linton 2014).

Meehan et al. (2020) outline several research priorities that they believe should shape future scholarship to dissolve the current notion of modern water and work towards more equitable water futures. This includes research that works to clarify the legal, political, and socioeconomic dynamics that produce conditions of water insecurity and research on the relationship between contamination, regulation, expertise, and trust. They call for efforts that "pay particular attention to the political and economic relations that produce conditions of pollution, community response, and impacts on human health and well-being" (Meehan et al. 2020). I answer this call through my investigation of power relations that have produced water contamination in Parkersburg, impacted women's health and well-being, and affected how women respond (or do not respond) to such contamination.

In so doing, my research contributes to critiques of the idea of universal "modern water" systems that ensure the equitable distribution of clean water in the global North. Moreover, scholars have called upon others to conduct more research in regions in the global North that are 
household water insecure. Specifically, Meehan et al. (2020) call on scholars to examine new and emerging contaminants, for example, PFAS or PFOAs, that threaten household water, yet are made invisible by common misconceptions of modern water. Accordingly, my research contributes to growing social science literature on PFAS contamination (Renfrew and Pearson 2021; PFAS Project 2020; Richter, Cordner, and Brown 2018; Cordner et al. 2019; Pearson 2020; Lyons 2007). These scholars examine the social factors that influence PFAS risk assessments, research, regulations, and community response. They identify several social factors that have impacted the production and dissemination of PFAS knowledge including industry sponsorship of toxicological knowledge, broad dissemination of industry-friendly research, and corporate influence in environmental regulation (Cordner et al. 2019; Renfrew and Pearson 2021). My research draws from and contributes to this literature through investigation of women's lived experiences of PFOA exposure at the household scale in the global North, and more specifically in the Appalachian region of the United States.

\subsubsection{Hydrosocial Waterscapes}

To combine societal and natural understandings of water, scholars have developed the key perspectives of the hydrosocial cycle and waterscapes. This approach deliberately places people at the center of water solutions (Linton 2014). The hydrosocial cycle is an approach to a hybrid understanding of water that critiques the Western scientific model of "modern" water. The hydrosocial cycle is a "relational-dialectical approach that demonstrates how instances of water become produced and how produced water reconfigures social relations" (Linton and Budds 2013). In other words, the hydrosocial cycle is the "socio-natural process by which water and society make and remake each other over space and time" (Linton and Budds 2013; Linton 2014). For example, we can view the hydrosocial cycle of contaminated public water. This polluted water is a kind of water produced by power and capital, or social relations. This produced water then changes societal relationships to water itself. For instance, people experiencing water contamination must then find alternative water sources, leading to consumption through private water companies. This shift from water as a public good to a commodity shows a turn in societal relationships to water.

The hydrosocial cycle demands that we ask what water is, how water is made known, and how water internalizes social relations, social power, and technology (Linton and Budds 2013). 
This framework allows researchers to analyze these social relations embedded in water and opens the potential of identifying sites for changing these relations (Linton and Budds 2013).

Complementary to the perspective of the hydrosocial cycle is "waterscapes". Waterscapes have been used to "explore the ways in which flows of water, power, and capital converge to produce uneven socioecological arrangements over space and time, the particular characteristics of which reflect the power relations that shaped their production" (Budds and Hinojosa 2012; see also Swyngedouw 1999; Bakker 2003; Budds 2008; Ekers and Loftus, 2008; Loftus 2009). A strength of the waterscapes approach is that it centers the geographical situatedness of water-society relations and makes room for detailed empirical case studies (Karpouzoglou and Vij 2017). In other words, waterscapes spatialize and temporalize the hydrosocial cycle. For example, Swyngedouw's (1999) study of water modernization in Spain explained the hybridity of water, part natural and part social, and highlighted the relational character of water as it flowed through physical, cultural, and social cycles and landscapes within Spain. Swyngedouw's $(1999,461)$ waterscape perspective raised questions of "who controls, who acts, and who has the power" to produce what kind of socionature, which has prompted many scholars to attempt to explain the dialectical relationship of capitalist development and the production of unequal socionatures (Karpouzoglou and Vij 2017; see also Sultana 2011; Kooy 2014).

The concept of waterscapes emerged from an array of interdisciplinary scholars including political ecologists that reject the notion that water is simply a biophysical or engineered substance. Rather, these scholars understand that there is a relationship between water and broader political economy and social power and that a complete understanding of water includes an analysis of historical-geographical struggles and how water-society relationships become embodied in particular landscapes (Karpouzoglou and Vij 2017). This question of the "natural" foundation of water and makes room for alternate ontologies of water, thus challenging the hegemonic position of Western science in defining what water truly is (Karpouzoglou and Vij 2017).

These questions of "who controls, who acts, and who has the power" are particularly relevant to my research, as power has emerged as a key factor in shaping the hydrosocial waterscape of Parkersburg, West Virginia. Specifically, the economic power of Dupont and the capitalist development of a harmful chemical compound contaminated the waterways of over 
100,000 people and led to transformed relationships between women and water. My research examines the waterscape of Parkersburg in an attempt to highlight the political and social forces that have shaped water access and use and how produced contaminated water has altered women's daily lives, well-being, and bodies.

\section{Chapter 3: Methodology}

The following section outlines my research methodology including the epistemological framework in which I situate myself, personal background and interest, positionality, and methods. The qualitative methods I used to conduct my research are thoroughly discussed below.

\subsection{Epistemology}

Feminist epistemology was at the core of my research process. Feminist theorists agree that knowledge is not objective, but rather is situated and informed by location, identity, and experience (Haraway 1988; Hiemstra and Billo 2017). These theorists criticize positivistic knowledge production that uses an epistemology where only certain people, typically highly educated academics or those with power, can create knowledge that is considered to be "true" through a research process based on traditional scientific research methods. These people have the power to ask certain questions, leave out or co-opt voices, and disseminate data in their preferred methods (Caretta and Riaño 2016). Furthermore, positivist generalizations exemplify the hierarchical nature of knowledge production and further the exploitative relationship that can exist between the researcher and the researched (Maynard and Purvis 1994; Caretta and Riaño 2016).

In my research, I used feminist methods when possible to avoid these harmful power relations and to create a mutually beneficial research project that values reciprocated knowledge and shared goals with my participants. Feminist methodologies involve co-determining research objectives with participants and involving them in the process of data analysis and dissemination (Caretta and Raiño 2016). This co-determination allows for an equal co-creation of knowledge rather than the hierarchical nature of more traditional methodologies. This acknowledgment of the power dynamics inherent to research allows for research outcomes that are more valid and rigorous (Guillemin and Gillam 2004; Caretta and Raiño 2016) 
I was unable to incorporate feminist methods into every step of my research process due to the time constraints of a two-year Master's program and various challenges that accompanied the COVID-19 pandemic. However, I was influenced by feminist theory and methodology and included these considerations in my research design. For example, I considered the lived experience and situated knowledges of my participants to be of great importance and through semi-structured interviews, sought to understand how women impacted by contaminated water conceptualize this contamination, as well as how it impacts their bodies and overall well-being. How one conceptualizes water contamination and risk looks different for each individual and using a feminist epistemology allowed me to gain a deeper insight into the everyday experiences of this phenomenon through these in-depth conversations and the centering of women's voices.

Feminist epistemologies also value the practice of self-reflexivity (Hiemstra and Billo 2017). Since the 1990s, feminist researchers have engaged in intentional reflexivity, which centers self-reflection in order to think through the myriad ways our identities, personalities, and place influences all aspects of research (Hiemstra and Billo 2017). My process of self-reflexivity included keeping a field journal that held notes from interviews, feelings that emerged during transcribing, and reflections during coding. Through this process, I maintained awareness that the results produced through my study were not neutral and objective, but part of a situated knowledge within itself (Caretta and Perez 2019).

Self-reflexivity also allowed me to better understand my positionality. I was able to identify specific moments where my positionality impacted participant answers and how my intimate understanding of place enabled me to share personal stories during interviews. I was often able to relate to my participants' stories, due to my familiarity with the culture and people of Parkersburg, thus allowing me to cater interview follow-up questions accordingly. Reflexivity, combined with flexibility in my research design, allowed for changes to be made throughout the process to better care for and understand my research participants. Some of these changes included rephrasing or altering the interview guide to include more pertinent questions and altering the method in which interviews were held and recorded.

Drawing on feminist practice, after the completion of my MA degree, I will co-create research dissemination strategies with my participants to ensure the project is mutually beneficial and facilitates an exchange of knowledge between myself and the participants. To do this, I will follow up with participants via Facebook Messenger or text message after the defense of my MA 
thesis, so that I can give more attention and care to the cause. Then, we will discuss if and to what extent they wish their story to be shared and the various strategies we could use to publicly display the study (i.e. website, podcast, library exhibit, etc.). After gauging interest from all of the participants, we will come to a consensus on dissemination strategy and work together to employ it. I will provide much of the labor in creating the display to ensure its completion.

\subsection{Personal Background and Interest}

I have a personal connection to the state of West Virginia and its residents. I was born and raised in Parkersburg, West Virginia, the site of my research, where I had first-hand experience and insight into the communities facing water contamination from the DuPont Washington Works plant. My grandparents both worked at DuPont. My mother and sister lived in one of the areas most impacted by C8 water contamination. My cousins were among the plaintiffs in the class-action lawsuit filed against DuPont. I distinctly remember going with members of my family to the pop-up C8 Science Panel testing building when they volunteered for the study. I remember the joy on my sister's face when she received that $\$ 400$-dollar check, the payment for getting blood drawn to determine the amount of C8 in her bloodstream.

My roots and experiences in different West Virginian communities have fostered a deep admiration and respect for the beautiful nature and kind, generous, and thoughtful residents. I have longed for a way to give back to my community and the place that fostered my growth. My attachment to place played a significant role in the framing of my research methodology. My research engaged in feminist methodology so that I could illuminate the often muted voices of women impacted by water contamination in West Virginia, foster empowerment within individuals, and ensure the reciprocation of knowledge. It is important to acknowledge my background and interest, as it impacts my positionality and informs my research process.

\subsection{Positionality}

The concept of positionality in feminist theory posits that each researcher is situated in a particular epistemological framework that is influenced by our gender, race, class, sexuality, ability, nationality, and other factors of identity (Hiemstra and Billo 2017). A researcher's positionality, combined with their biography, influences how one conducts research, interacts 
with the field, and analyzes data. With this, research is personal and must not be considered to be solely objective (England 1994).

My identity as a healthy, young, white, lower-middle-class, childless, educated woman from Parkersburg, West Virginia influenced how I collected data, how I analyzed it, and how my findings will be disseminated. Not only did my identity affect my process of conducting research, but it also affected how participants responded to the questions I sought to answer. For example, many of my participants were immediately comfortable sharing personal information like complications with their reproductive health, with one woman attributing her comfortability to our shared identity by saying, "we are both women here." My achievement of a successful qualitative research project was in part dependent on participants' perceptions of me and how well they trusted me based upon these features.

As a former resident of Parkersburg, I was considered among other resident participants as an "insider," due to my lived experience and intimate understanding of place (Taylor 2011). Some advantages of an insider perspective include a deep level of understanding through previous knowledge of the field in which you are working, closer contact with the field and participants within it, more detailed understanding of the social, political, or economic factors at work in the particular area, and quicker establishment of trust (Taylor 2011). These advantages manifested in various ways throughout my research process. For example, women would discuss certain places within the region that had experienced a high level of contamination or where many residents had reported illnesses, and I was often able to recognize these places, leading to a more detailed understanding and visualization of impacted areas.

In some cases, my positionality as an insider complicated the conversation between myself and the participants. Some women assumed that I had a particular knowledge about the area and did not answer prompts to their fullest potential. For example, when talking about the pervasiveness of DuPont in the Parkersburg region, some women would hint that it was information I already knew and they need not expand further. I would often have to ask for clarification and imply that I knew little about the topic so they would explain their full feelings to me.

Another challenge of operating within an "insider/outsider" binary is that the boundaries are often loose and the researcher can float between them given certain aspects of their identity. I was raised in Parkersburg but haven't lived there for over 7 years and have lost a certain 
familiarity with the region. With this, I rest in a grey area between insider and outsider because of the time and space between myself and the place.

Although I have demonstrated both challenges and advantages in doing insider research, I believe that the benefits are numerous and lead to a deeper understanding of the research site and participants' lived experiences. However, insider research is not without fault and does not offer an absolute or correct way of seeing, rather it is one of many ways of seeing (Taylor 2011).

I am in a privileged position within academia where the "data" collected can be categorized as "knowledge." In my research, I listened to and talked with women who have lived through experiences of water contamination and each of their stories is "truth" in and of itself. I illuminate their voices using my privileged position and hold space for communities and individuals whose voices have been silenced, erased, or excluded (Cahill 2007).

\section{$\underline{3.4 \text { Methods }}$}

Due to the personal, contextual, and political nature of my research topic, I used a qualitative approach rooted in feminist theory and methodology in my research design. Critical feminist perspectives on geographic practice influenced the turn to qualitative methods in the 1980s and shone new light on social and spatial processes that were frequently overlooked in the past (Cope 2010). Qualitative research can contextualize large-scale findings, provide nuanced understandings of complex processes, and elicit the meanings of phenomena through people's lived experiences (Cope 2010).

In my research, using qualitative methods illuminated individual perspectives and enabled me to gain a deeper understanding of the social, economic, and environmental factors that shape one's perspective of water contamination. Feminist theory encourages the researcher to view their own methods and practices with a critical eye through self-reflexivity and attention to positionality, both of which I account for in my research design (Cope 2010).

In the following section, I describe the boundaries of my case study, my purposeful and snowball sampling strategies, and my process of conducting semi-structured interviews in a time of a global pandemic. I go on to describe my data analysis process which included transcribing interviews, coding with Atlas.ti, member-checking, and synthesis through writing. Finally, I describe possible avenues for dissemination after the conclusion of my Master's degree. 


\subsubsection{Case Study: Parkersburg, West Virginia}

The purpose of a case study is to gain a deep understanding of a bounded or specified phenomenon, rather than research designed to conclude with universal or generalizable theory (Marby 2012). Therefore, a case study approach was appropriate for my research design, as I sought to understand the lived experiences of women impacted by $\mathrm{C} 8$ contamination in and around Parkersburg, West Virginia. The data that I gathered was specific to current or past residents of Parkersburg, West Virginia who experienced water contamination via DuPont, bounding my research to a specific place through time.

To answer my specific research questions, I prioritized interviewing people who identify as a woman and have lived or currently live in locations most impacted by water contamination in the Parkersburg region. These locations included Little Hocking, Ohio; Washington, West Virginia; Vienna, West Virginia; Parkersburg, West Virginia; Belleville, West Virginia; and Lubeck, West Virginia. I chose this specific demographic due to my feminist epistemological considerations that wish to explore and illuminate voices that have been traditionally silenced (Cahill 2007). I chose to examine Parkersburg, West Virginia, rather than other geographic locations where DuPont has contaminated water sources (i.e. Fayetteville, North Carolina) because of my personal connection to the location and the growing awareness of PFOA exposure in the region.

\subsubsection{Sampling Strategy}

I used purposeful and snowball sampling when selecting interview participants. Purposeful sampling involves identifying and selecting individuals or groups that are especially knowledgeable or experienced with a certain phenomenon (Cresswell and Plano Clark 2011). In an attempt to find a diverse pool of research participants with personal connection to C8 contamination, I posted on a widely popular private Facebook Group titled, "MOV - What's Happening." In March 2021, the group had over 44,000 Facebook users from the Mid-Ohio Valley (MOV) region, including Parkersburg, with over 1,000 posts shared in the last month. I posted a short paragraph describing my research, ideal participants, and conditions of anonymity. Within a few days, I had received 58 comments and over 60 private Facebook messages from women who were interested in being part of my study. 
In these private Facebook messages, I asked open-ended questions to learn more about their connection to $\mathrm{C} 8$ contamination so that I could determine if they were appropriate interviewees. I selected those who had confirmation of C8 contamination either through participation in the C8 science panel testing and/or those who had lived or currently live in areas with confirmed water table contamination. After we discussed their connection to $\mathrm{C} 8$, I asked if they were interested in speaking with me in a one-on-one conversation via Zoom or telephone. Most of the conversations leading up to the interview were done via Facebook message, with one being done over text messaging. Keeping all correspondence over Facebook messaging allowed me to better organize messages and manage the timeliness of my responses. Towards the end of the actual interviews, I initiated snowball sampling.

Snowball sampling involves tapping into a network of participants, in which participants make a series of referrals for future participants (Browne 2005). One benefit of snowball sampling, used in addition to purposeful sampling, is the ability of the researcher to access a network of people that they may be unfamiliar with otherwise. In my study, I asked the participants if they knew anyone else who might be interested in speaking with me and encouraged them to reach out to these potential participants. I preferred them to make initial contact, so the potential participant would feel more comfortable reaching out to me themselves. Through this strategy, I was able to interview three other women who I would not have been connected to otherwise.

\subsubsection{Interviews}

I conducted 18 in-depth, semi-structured interviews to answer my research questions. I chose to conduct semi-structured interviews rather than structured or unstructured, so that I could create a conversational, yet guided flow and allow for an investigation of opinions, emotions, and a collection of diverse perspectives (Baxter and Eyles 1999; Longhurst 2003). A unique aspect of this research is that it was created and carried out during the COVID-19 pandemic. Conducting research during a pandemic presents unique challenges that I accounted for in planning and implementation. For example, I maintained flexibility when working with participants' schedules and uncertainty in their day-to-day or weekly availability, as well as difficulties in internet connectivity. 
The first three interviews were conducted using Zoom. Zoom is a collaborative videoconferencing tool that offers a space for online meetings and messaging. Geographically distant users can communicate in real-time on computers, tablets, or mobile devices. On Zoom, you can record and safely store the entire video conference, a feature I imagined to be greatly beneficial in the data analysis and archival process. Unfortunately, due to consistent difficulties in internet connectivity, I quickly adjusted strategies and decided it was best to conduct the remaining interviews by telephone only.

An interview guide, used in all semi-structured interviews, was created and refined multiple times before use in the interviews. The guide was discussed in collaboration with my committee members before my first interview. Together, we made changes on my proposed guide until we felt the questions adequately covered topics related to my research questions. The participants were asked all questions on the guide, unless they had answered the question earlier in the conversation. The interview guide (see Appendix A) included three subsets of questions that directly corresponded to my three main research questions: What are women's understandings of risk associated with household water contamination caused by the DuPont Washington Works plant in Parkersburg, West Virginia? How do these understandings and experiences of risk impact women's bodies and overall well-being? And what are women's hopes for the future of water quality in Parkersburg? The guide was designed to give direction to the semi-structured interviews with room for participants to elaborate and to give me a better understanding of their individual lived, everyday experience (Longhurst 2003).

Prior to each interview, I explained the terms of confidentiality and asked each participant to give verbal consent to being recorded. After gaining IRB approval and in accordance with their requests, each participant received a cover letter either by email or Facebook message that contained a description of the project, confidentiality, and IRB details. The first three Zoom interviews were recorded through the software and securely stored on my personal computer. A backup of the data was then saved on my personal Google Drive account, which is password protected. The remaining interviews were conducted via telephone using the speakerphone function. I conducted these conversations in a private room on speakerphone, and then would use my personal tablet to record the sessions. The phone call recordings were then sent to and stored on my personal computer, with a backup stored on the same Google Drive account. The participants were made fully aware about being recorded and were given the option 
to decline if they felt uncomfortable, although no one did. In addition to the recordings, I kept a field journal where I jotted down key quotes, themes, and feelings about each interview.

\subsubsection{Field Diary}

I maintained a field diary that contained notes of my emotions and experiences during the research project (Watson and Till 2010). A field diary can offer "rich descriptions and detailed accounts that depict the worlds, environments, peoples, contexts, and meaning-makings we have researched, engaged in, and learned from" (Watson and Till 2010). Maintaining a field diary allowed me to be reflexive in my experience, a key concept in feminist theory (England 1994). I kept note of personal emotions or feelings that emerged during interviews, for example, moments when I felt shocked, sad, or hopeful in response to a participant's story. Keeping field notes also enables researchers to explain how they have interpreted their data, the steps in their research process, and to provide insight into any changes or challenges that occurred in their research questions or methods (Deggs and Hernandez 2018). This type of reflexivity adds to the validity of the research, as you can easily trace errors or revelations.

For my research, I used notes from my field journal to create a preliminary coding list, as I had often noted key themes that emerged from each interview. My field journal also provided insight into various issues I was having with the Zoom software, which helped me make the decision to switch to phone interviews only. I uploaded my field notes into the qualitative data analysis software, Atlas.ti, in order to securely store them and code them with my other data.

\subsubsection{Validation}

In order to maintain transactional validity and rigor in my research, I used triangulation, peer debriefing, member checking, and a reflexive field journal (Cho and Trent 2006; Long and Johnson 2000). Transactional validity is grounded in active interaction between the inquirer and the research participants (Cho and Trent 2016). Regarding triangulation, I compared perspectives from multiple participants to ensure an authentic representation of the experience, i.e. credibility (Baxter and Eyles 1997).

Another way to ensure credibility is through peer debriefing (Baxter and Eyles 1997). To peer debrief, I consulted academics in my department, like my advisor and other members of the Center for Resilient Communities, to ensure that my analysis of the data made sense and fostered a connection between the responses and my interpretation. During the interviews, I used 
communicative validation. This consisted of immediately repeating or paraphrasing a participant's response to ensure that I was hearing and recording the data correctly, which ensures dependability (Baxter and Eyles 1997).

Member checking occurs throughout the preliminary data analysis process where the researcher checks with the participants to ensure that their interpretation of the data is correct, ensuring credibility once again (Cho and Trent 2006). To member check, I shared my themes or realizations with my interviewees to ensure that I had drawn correct conclusions. This occurred after my coding process, and I shared with them key themes that had emerged from their individual interview. Upon approval, I continued on in the process of data analysis.

\subsubsection{Data Analysis}

My strategy for data analysis included transcribing all interviews and coding these interviews in multiple rounds. I transcribed my interviews using an online transcription software called Otter.ai. This software automatically transcribes audio files once uploaded but is not wholly accurate. Therefore, after each recording was automatically transcribed, I went back through, listened to the recordings, and corrected misspellings or instances of false transcription.

When coding, I used the computer-aided qualitative data analysis software, Atlas.ti. Coding refers to the process of categorization or creating identities based on common themes throughout different sources (Cope 2019). Atlas.ti aids in storing, organizing, coding, and analyzing qualitative data, but by no means does it do these functions automatically (Cope 2019). When you code in Atlas.ti, you are the one "telling" the software where the interesting or key themes are in the data (Friese 2019). By naming something in Atlas.ti, I conceptualize it and frame it at the same time (Friese 2019).

Before I began coding using Atlas.ti, I created a draft list of potential coding themes using my field journal, themes I remembered from interviewing and transcribing, and some grounded in political ecology and water studies. The codes I created can be categorized as both emerging and predetermined (Creswell and Creswell 2017). Emerging codes are codes that appear during the data analysis process, while predetermined codes are based on theory (Creswell and Creswell 2017). For predetermined codes, I looked for words that related to "modern water" and "hope", both being concepts that I had expected to materialize in the interviews. I also used emerging codes, including "reproductive health" and "power," that 
surfaced while reading through multiple interview transcripts. After I created this initial list, I reviewed it with my advisor, Dr. Shinn, to ensure that I was conceptualizing and justifying codes properly. Next, I added the draft list of codes into Atlas.ti as "free codes", meaning they were not yet attached to specific quotations or lines in any transcription.

In my first round of coding, I attached these codes to various quotations or words, occasionally adding codes that I previously hadn't considered. I repeated this cycle several times until no new themes or codes were emerging. Next, I engaged in the process of "winnowing" the data, or focusing in on specific data and disregarding other parts or themes (Guest, MacQueen, \& Namey 2012; Creswell and Creswell 2017). The goal of this process is to aggregate the data into a smaller number of themes, with Creswell and Creswell (2017) recommending between five and seven themes. In accordance with this recommendation, I consolidated specific codes into broader themes until I had 7 main code groups: water, risk, place, power, health, gender, and hope. A detailed list of main code groups and their sub-categorized codes is outlined in Appendix B. The key themes that emerged through coding were made into corresponding subsections within my findings section.

When writing my findings section, I revisited each code group in Atlas.ti and examined the attached quotes. I sifted through the quotes and copied the most relevant ones over onto a new document, maintaining the various code groupings. From here, I narrowed down the quotes once again and arranged them in a manner that created a cohesive story and ensured I forefronted the voices of my research participants. Once I began writing, I inserted the quotes into the working document until all main ideas were explored.

For the sections on Modern Water (section 4.1) and Reproductive Health (section 4.4), I created a separate Excel spreadsheet where I matched names and pseudonyms with direct experience of certain phenomena (Appendix B). This was necessary so that I could keep track of the multiple illnesses women reported at different parts of the interview and helped me to make clear connections between illnesses and perceptions of risk and water quality. For example, I counted the number of people who personally suffered from various reproductive and thyroid disorders to accurately make my case in the Findings chapter. For section 4.1 on Modern Water, I explored correlations between perceptions of clean, safe, and reliable drinking water with those who experience no health concerns. The use of these spreadsheets allowed me to better visualize 
the data and draw accurate and comprehensive conclusions. As an example, the spreadsheet used to analyze women's health is shown in Appendix B.

\subsubsection{Future Dissemination}

Research dissemination is the written or oral representation of project findings, typically at the end of a research project (Keen and Todres 2007). As my research project is influenced by feminist participatory methodology, dissemination is greatly important as it will ensure reciprocation of knowledge (Cahill 2007). Those who engage in a participatory theoretical framework believe that there is an ethical obligation to share results with the participants (MacKenzie et al. 2013).

As the desires of the researched community are of great importance in participatory research methods, I will be asking participants what their desired outputs are and to which audience they are interested in reaching (MacKenzie et al. 2013). This will be determined after the completion of this MA thesis but may include dissemination in the form of website creation, a podcast, or a library exhibit.

In 2022, I intend on presenting my findings at the American Association of Geographers Annual Meeting and the Dimensions of Political Ecology conference held annually at the University of Kentucky. I chose to abstain from presenting in 2021 due to the ongoing challenges that accompany the COVID-19 pandemic.

\section{Chapter 4: Findings: Experiences of Water Contamination, Risk, Power, Health, and Hope in Parkersburg}

\subsection{Disrupting the Myth of Modern Water through Examination of the Parkersburg Waterscape}

Each of the 18 women I interviewed has a complex relationship to water, as perceptions of reliability, cleanliness, and level of safety differed from person to person with various factors influencing their specific relationship. Recently, several interdisciplinary water scholars came together to suggest that the idea of "modern water" is a myth depicting widespread household water security in the global North (Meehan et al. 2020). My analysis of the hydrosocial waterscape of Parkersburg, WV supports calls from these authors to dispel the myth that water is universally clean, safe, trustworthy, and accessible in high-income countries. Rather, I find that 
my research participants are water insecure, as a result of a "lack of safe, reliable, sufficient, and affordable water for a thriving life" (Jepson et al. 2017).

\subsubsection{Water Access and Procurement}

The myth of modern water suggests universal access to water. However, in Parkersburg, water contamination by $\mathrm{C} 8$ has decreased access to clean water and altered many of my research participants' water procurement strategies. For example, obtaining water through potentially contaminated wells has become less and less desirable, forcing women to turn to more expensive alternatives. At one point in their lives, seven of my participants relied on a well to provide their drinking, bathing, and cooking water. Oftentimes, a well was their only source of water, especially for those who lived outside of municipal service areas. Lack of access to municipal water increased water insecurity for a number of women. One participant, Hailey ${ }^{1}$, described in detail the arduous task of procuring water in her childhood home, where they had no access to municipal water. Hailey's story is a clear example of a household experiencing water insecurity and exemplifies that water in the United States is not always universally accessible. She explained:

"When I was a kid growing up, we had two sources [of water.] We had a spring that drained into a well on our property. It was filtered from the ground, but it was not filtered from C8. And then we also hauled water because the spring would not produce enough in the summertime. So my dad had a truck that we would haul water from the old Fire Department in Lubeck. Then we got public water when I was in high school or college. We had a terribly old truck that had a huge tank on the back of it. And it would fill up both of our wells. My dad had buried concrete tanks in the ground that we would put the water into.

There wasn't any relying on the spring. It was there as needed, but in order for us to have water, we had to ration our water. So you know, extra things like washing vehicles, mom doing laundry, those kind of things, had to be limited a little bit just because we didn't always have water.

\footnotetext{
${ }^{1}$ All names referenced in this thesis are pseudonyms.
} 
If it were getting towards the bottom of the tank, mom would not wash laundry because it'll all come out brown. My dad drove trucks and worked midnight shift. So we would have to plan when we would get water based on his two days off through the week. So we would always have to plan when we were going to get water based on those days. And then kind of shift everything else around on what we were doing in the house."

The water that Hailey's family accessed via their spring and through hauling was contaminated water produced by DuPont and more broadly, social relations. After her family learned of the contaminated water, they altered their relations to the water itself by finding an alternative water source. Their relationship to water shifted, as they went from obtaining water as a public good to commodity, and then back to public good when they gained municipal water. Eventually, Hailey developed illnesses due to this produced water which had great impacts on her body and well-being.

Hailey's story illustrates how DuPont produced a certain type of water that reconfigured the relationships people have to water within Parkersburg, including by forcing them to seek alternative household water procurement strategies. Hailey's story also touches on the unreliability of water sources in the Parkersburg region. When asked if they felt their water source was reliable, eleven women responded that they felt it was reliable, despite also describing the water as unclean or unsafe. In several responses, women explained that they never feared that water would not flow from the tap. However, their understanding of water reliability was nuanced, as they explained that they were confident they had reliable access to water, but were unsure of the cleanliness of that water. For example, Suzy responded:

"Well, reliability is an odd question. When you turn the faucet on, water comes out. But I would not consider it reliable in the fact that it was always unclean.”

Six women explained that they did not think their water was reliable. Four of the women who characterize their water as unreliable source their water from a well and described considerable issues that impacted their well water's reliability. These issues include faulty pumps, wells running dry, or water coming out with high turbidity. Other women who spoke of unreliable water discussed poor water infrastructure in their communities. Two women reported 
that water main breaks in their water districts led to turbid water and the issuing of boil water advisories, and one woman explained that her household has been issued three boil water advisories in the past year. This is significant because "aging water infrastructure increasingly fails to provide the kind of clean water people have come to expect" (Allaire, Wu, \& Lall, 2018; Grigg, 2019; Kenney et al., 2019; Meehan et al. 2020). Instances of poor water infrastructure actively dispel the modern water myth that infrastructure networks and water services are uniformly distributed with similar quality across cities and regions of the Global North (Meehan et al. 2020).

Many women seek alternative water sources like filtered or bottled water to avoid contamination from tap or groundwater. Specifically, twelve women use bottled water as a primary source of drinking water and ten use filtered water, with some accessing both sources. Ten women reported that they actively avoid drinking tap water, and will only occasionally use it for cooking purposes. Jane shared this sentiment:

"We won't even use the city water for our animals because there's so many chemicals in it. We don't completely know exactly what all is in there. We don't know exactly what could be seeping into that water. And the fact that once you go from drinking so much bottled water to having a taste of tap water - you can taste that chemical difference, then it's just, 'this does not seem safe."'

\subsubsection{Trusting safe and clean water}

Another aspect of the myth of modern water that my analysis of the Parkersburg waterscape disrupts is that of widespread trust that water is clean and safe. Eight of my participants reported that their water was safe and clean, and of these women, four report no related health concerns. Although these women were aware of the potential contaminants in their water, they felt it was clean enough to consume because they had personally not experienced any health impacts. For example, when asked if her tap water is clean and safe, Becky explained:

"Well, it's clean, I believe, as far as it runs clear. Safe. I have been drinking this water for 42 years and it has not affected my health, that I'm aware of. I do use it for cooking and bathing. My pets drink it. So I guess, yes, I feel like it's safe enough"

Similarly, when I asked if Sally felt her water was safe, she said: 
"Safe in moderation. I mean, I don't have any health problems. So it's not like you're gonna drink the water and you're gonna die. I wouldn't say that. I mean, I would just say it could be potentially harmful. It's been proven to be and so that's why I am weary of it. But I mean, I don't think everyone who drinks the water is going to have a problem."

Over half of the women I spoke with believe that the water from their tap is not clean or safe. The majority of these women have one or more health issues that they believe are connected to C8 contamination. For example, when I asked Kelsey if she felt her water was clean and safe, she said "no" and described her and her family's extensive health issues and explained that they all lived on the same street and drank the same water. In this case, a woman's perspective of clean and safe water was connected to her lived experience of health concerns connected to contamination. Many of these women no longer consume tap or municipal water because of their fear of contamination.

Other women I interviewed described their tap water as unclean and unsafe, yet they drink the water anyway. Some of these women had severe health issues that were directly connected to $\mathrm{C} 8$ contamination, but they continue to drink tap water because of its availability and ease of consumption. When asked about the cleanliness of her water, Lindsey explained that:

"I know that it's not [clean]. I know that it's not what it's supposed to be. Is it better than what most people get? Yeah. So what if I rated it like 65 percent? Like its passing? Do I know that it's been bad for me and has probably caused problems in my life? Yes. But I just roll with it. Which is probably not wise... but my thoughts are there are people in the world that are getting their water from a puddle. What $\mathrm{C} 8$ is going to do to me compared to what.... We're still really blessed in our little Chemical Valley in comparison to the majority of the world."

Although Lindsey has several known health issues that are connected to $\mathrm{C} 8$, she still drinks the water because it is not "as bad" as what others are drinking in the world. This finding ties back again to the concept of "modern water", which posits Western models of water management and access as supreme compared to the global South. This comparison renders those who experience water insecurity in the global North invisible, as the myth of modern water creates and sustains norms and perceptions of secure water in places like the United States. 


\subsubsection{Distrust of water quality reports}

Some of those who abstain from drinking tap water explained that their abstention stems from a distrust of water reports that claim tap water as safe for consumption. Information about water quality, as described by my participants, comes from a variety of sources including local news, Facebook friends or neighborhood groups, municipal water departments, and DuPont contractors. Public water services are common in the Parkersburg region, with many getting their tap water from the Parkersburg Utility Board or the Lubeck Public Service District (PSD). Periodically, the water departments will send out letters to their customers that explain the level of contaminants, including the amount in parts-per-trillion of $\mathrm{C} 8$ in their water.

Located on the front page of the current Lubeck PSD website is a small disclaimer about the presence of C8 in local drinking water (Figure 3). The letter states that DuPont installed an activated charcoal filtration system within the Lubeck PSD and reported that there was "no measurable level of C8 in the filtered water." Contrarily, the Lubeck PSD follows this statement by saying that they cannot "guarantee that its water won't contain any $\mathrm{C} 8$ in the future, nor does it have the capacity to determine whether any given level of C8 in its drinking water is harmful." 


\section{LUBECK"

October 25, 2007

To all present and future water customers:

Lubeck Public Service District remains committed to providing good quality drinking water to its customers and we believe we are achieving that goal at the present time.

There is, however, a controversy as of the date of this letter about the effect of ammonium perfluoroöctanoate ("C-8") in the area. The question whether C-8 poses an unacceptable risk to those who are exposed to it is under study at the present time and no definitive answer is available.

Drinking water processed and delivered by Lubeck Public Service District is now undergoing activated charcoal filtration by DuPont to remove C-8 from our water supply. As of the date of this letter, this type of filtration has occurred for several months and DuPont reports to us that there is no measurable level of C-8 in the filtered water. Despite this filtration process, Lubeck Public Service District cannot guarantee that its water won't contain any C-8, in the futurc, nor does it have the capacity to determine whether any given level of C-8 in its drinking water is harmful.

Accordingly, you must make your own decision whether to continue to use our water for human consumption. If you desire to have more information about C-8, there are governmental agencies, websites and other resources available containing additional information. If you elect to use water supplied by Lubeck Public Service District, you do so at your own risk and Lubeck Public Service District is not responsible or liable for any claim, action or matter arising from the presence of C-8 in drinking water processed by it and provided to its customers. We apologize for any inconvenience or dislocation these circumstances may cause you but they are beyond our control.

Yours very truly,

$\mathrm{JMC} / \mathrm{rah}$

LUBECK PUBLIC SERVICE DISTRICT,

Revised: October 25, 2007.



Figure 3: A letter currently posted on the Lubeck PSD website to customers explaining that their tap water might contain traces of C8 contamination. Source: https://www.lubeckpsd.com/Portals/LubeckPSD/docs/C8.pdf?ver=2009-11-17-144110-000

Although C8 is of current concern, the outdated letter was published in 2007. This represents the lack of urgency and care that water departments place on $\mathrm{C} 8$ contamination within the Parkersburg region, which increases distrust in municipal water transparency and ethics. When asked why she distrusted the water quality reports from her municipal water department, Lindsey explained:

"Probably just the pretty deep-seated history in this area of not telling the truth or trying to cover up what could possibly hurt us or will hurt us. So I think that that trust is gone. I don't think that that will come back where people are like, "Oh, I do trust the water company after all." 
The deep-seated history Lindsey referred to involves DuPont covering up their deliberate contamination of local waterways, and many residents believe that local water departments knew what was occurring and refrained from telling the public.

Another issue women spoke about regarding municipal water quality reports is the complex language used to describe present contaminants and their lack of scientific understanding. When asked if they believed that water quality reports presented accurate information, seven women responded that they do not trust the data because they do not understand it. For example, Sally stated:

"When we had Parkersburg city water, they would send out letters about the quality of water, and blah, blah, blah. But I mean, it doesn't make any sense to me what they're talking about. So I just skim it, and then throw it away. When I read that stuff, it's all scientific things. And I don't know what that means."

Generally, these reports state that the level of C8 contamination is within "healthy standards". However, this type of risk assessment is often debated as water experts use a techno-scientific approach to understanding risk that doesn't fully take into account the general population's lived experience (Meehan et al. 2020). For example, although the Environmental Protection Agency (EPA) designates the safety threshold of C8 contaminated waterways to be 70 parts-per-trillion, the US Department of Health and Human Services has determined the safety threshold of C8 to be almost seven times lower than EPA's guidelines, at 11 parts-per-trillion (Volcovici 2018). According to the national nonprofit, the Environmental Working Group, in 2017, there were 63 parts-per-trillion (ppt) of C8 detected in Parkersburg waterways, $129 \mathrm{ppt}$ in the nearby city of Vienna, 360 ppt across the river in Belpre, Ohio, and 2,500 ppt just down the river in Little Hocking, Ohio (EWG 2021). The discrepancy between various standards is due to the lack of scientific or medical testing on short-term exposure to $\mathrm{C} 8$, as these studies are hard to administer due to exposure risk on human health. The EPA has based their findings on peer-reviewed studies conducted on C8 exposure in laboratory animals, which do not account for lived human experience.

The experiences of my research participants demonstrate the various ways that the Parkersburg waterscape disrupts the idea of a universal modern water that portrays the equitable distribution of clean, safe, and reliable water in the global North. In reality, experiences of household water insecurity in the global North, exacerbated by instances of water contamination, 
are often made invisible by the myth of modern water. The voices of my research participants illuminate the importance of these often silenced stories.

\subsection{Perceptions of Risk in a Contaminated Community}

Women's household water security is in part dependent on their perceptions of risk related to exposure to contaminated water. Some women feel significant risk in consuming contaminated water and connected level of risk to personal health issues, therefore they abstain from drinking tap water. Some feel their contamination "isn't that bad" or that they have to prioritize other environmental risks over the risks inherent to consuming contaminated water, which leads to continued tap water exposure. While others feel little to no risk because the cleanliness of their tap water is never something they stop to consider, as they assume it is safe because nothing has ever presented itself to make them think otherwise. Research on lived experience of risk is important, as it becomes a valuable tool in developing less biased and more accurate assessments of risk and can facilitate the creation of people-centered solutions to environmental threats (Checker 2007).

When asked about their understanding of risk due to $\mathrm{C} 8$ water contamination, 13 women connected their level of risk to personal or familial health problems. They were aware of the risk because there was a tangible outcome of water contamination that they were unable to ignore. For example, when asked about the risks of water contamination, Kaitlyn responded:

"There could be any health risks. Because what I went through showed me that. It could go deep into your body and cause problems."

Three women were aware of the risks of C8 contamination through a personal connection to someone who worked for Dupont. They felt that their family members experienced great risk by coming in direct contact with $\mathrm{C} 8$ production and then brought that contamination home through their clothing. Sarah reflected on how her father's experience working at Dupont impacted her awareness of $\mathrm{C} 8$ at a young age:

"I can remember when I was little. [My father] would always come home and change clothes and take a shower because he smelled. We would say that 'he smelled like DuPont.' You'd notice it. And then he always left his work shoes outside because they 
smelled so bad. And then sometimes it'd be so strong, it would make your eyes burn. That increased my awareness more than anything."

Britney also explained her fear of the risks involved with C8 exposure following her husband's employment with Dupont:

"My husband worked at DuPont for a short time. And that was like a huge risk for us. That really scared us because he worked in the Teflon department too. And it was just not something that we wanted him to be directly exposed to. He always had this weird metallicky smell. And when he would come [home], the chemicals went through his clothes, and would bleach his jeans. And we were constantly buying safety glasses because the Teflon would literally itch at him through the plastic of the glasses. So he didn't stay in that department long at all. It's just dangerous."

For these women, their perception of risk involved their past experience with DuPont and it shaped how they understood the possible effects of contamination. The strong smell and obvious exposure to chemicals increased their awareness of the risks inherent to $\mathrm{C} 8$ exposure.

Three other women described increased awareness of risk due to their proximity to DuPont and their dumping sites. One woman, Hailey, explained that growing up her family only lived around one mile from the Lubeck dump where DuPont had hauled a lot of C8 byproducts. She said:

"Word of mouth also spreads pretty quick down here. So our property is not far from all of the mess that they were creating and then filled over. And then as soon as we realized that there was an issue, everything kind of started clicking as to why everybody was having so many problems. And that's when it kind of all started coming to light that there was more to this story than what we had originally thought. I think we were as contaminated as anybody could be, given the fact that our water was coming from the ground less than a mile from the dump site. So, yeah. I feel like we were pretty highly contaminated."

Another woman, Suzy, told me that she experienced greater risk than others, because she ate fish out of Washington Bottom Lake, a lake that is known to be greatly contaminated, and she drank well water that contained poisoned groundwater. However, at the time of consumption, 
Suzy perceived the risk of contamination to be very little because she had no health concerns. She explained that even though she knew the water was contaminated, she drank it anyway. She said:

"My house is at the lake and I parked at the bottom of the hill and I had 80 steps to walk up to get to my house. So for me living alone and carrying water up that hill wasn't feasible. And I just thought, well, it hasn't killed me yet. I mean, we knew that it built up in your system, that it was a cumulative type contaminant. And I figured, well, Hell, I've had about ten years of this at the highest doses you could possibly have so why am I going to try and carry cases of water up this hill?"

In this sense, Suzy thought little of the possible impacts of exposure and concluded that the risks were "not that bad." However, Suzy's perception of risk changed when she was later diagnosed with high cholesterol, reproductive health issues, and an autoimmune disorder that she believes are connected to C8 contamination. This is not unique to Suzy, as other women who were not experiencing health effects also decided that the risks were not bad enough to make lifestyle changes.

One woman, Sally, went as far to say that consuming contaminated water had developed into a "norm" or "habit" that she felt little risk from because her and her family remained healthy. Sally explained that while she believed her health might be at risk due to contaminated water, but that she, "just doesn't think about it all the time" and that it is, "not something that weighs on her mind." Another woman, Brittany, echoed this sentiment. She explained that while her local water quality reports list several contaminants in the water, she drinks it anyway because drinking water from the tap is a normal activity. She said:

"It's just a part of your life. Like, I don't even think about it. It's just like you're mindlessly drinking water. I don't think about what it's doing [to me]. My entire family still drinks from the tap. They still drink the same way I do even though they know C8 is harmful. [Contamination] is just normalized and it's never discussed. It's just kind of like, 'Oh, yeah, there's C8 in our water. Hahaha. Just kind of how it is."'

Brittany and Sally's perception of risk is influenced by their lack of immediate health concerns. They don't feel the need to make changes in their daily life, even though they are aware of the potential health effects. Like many in the Parkersburg region, they have accepted that the water 
is contaminated and continue to drink tap water due to its ease of access. This response relates to the idea of denial, one of Langford's (2002) types of environmental threat response (discussed in section 2.1.1). Denial, in this sense, means that these women respond to water contamination by minimizing the consequences of toxic exposure, allowing them to go on with their daily life stress free.

Seven women discuss perception of risk as it relates to risk prioritization. They explain that in the Parkersburg region, there are many other things to worry about besides water quality. These worries include: food security, the opioid epidemic, physical safety, and money troubles. For example, Kelsey explains:

"In Parkersburg, specifically, people aren't focused on their health or doing much of anything other than day to day survival. So it's really easy when you have a community that's basically trying to live hand to mouth, survive, deal with an opioid addicted population, and a rundown city, to not worry about the water. Unless somebody they know is sick."

Rhonda shares these feelings:

"In your day to day life, as long as that water will turn on... If you've got kids, a family, and you're busy... You work, Your husband works. Your car breaks down, you got problems at work, whatever it is. As long as when you turn that water tap on and you have clear water, that's all you need. That's what most people worry about. Life is too short to worry about what you can't change. So, I've got more important things to worry about."

To these women, the risks associated with these other factors outweigh the risks of water contamination. They feel that the risks of water contamination are out of their control, so they choose to focus on things they feel are more likely to change. This response to water contamination relates to apathy, a type of environmental threat response that involves claiming an inability to do anything about the environmental threat as a way to maintain mental wellbeing (Langford 2002; Sullivan and Young 2020). Women use apathy to mitigate their stress levels by allowing themselves to let go of the worry of water contamination.

Then, there are women who, in the past, perceived no real risk from water contamination. Kelsey touched on this in her interview by explaining that people do not generally stop to think about water contamination, therefore they do not perceive inherent risks. She said: 
"It is just not something you think about. You trust your government, and the people running things to keep you safe. We are 5 miles from the river and 12 miles from DuPont. Why would we have [contaminated water]? Because it's leeched in but that's not something you think about until you have an issue, and you have to [think about it.]'

Becky also discussed her lack of perceived risk, explaining that:

"It's almost like if it had shown up discolored or smelled funny. Or any evidence beyond reading it in the paper, then it would have been like, "oh, well we're not drinking this." I mean it's in the paper, I completely think it's true. But It was just like, "Ehh, this must be okay. It hasn't hurt us."

For Becky and others, the cleanliness of their water and level of risk can be determined by appearance of contamination. This means that clear water is clean water and is therefore associated with no risks. Often, these women made no changes to their daily lives in regard to water procurement and drank from the tap as normal. Accordingly, their perception of risk (or lack thereof) impacted the ways in which they viewed water contamination.

Finally, even when women identified the myriad risks associated with consuming contaminated water and living in Parkersburg, all 18 women have chosen to remain in Parkersburg due to strong attachment to and sense of place. In many cases, they were able to overlook the risks due to their strong attachment to place. When asked why they remain in Parkersburg despite the risks of contamination, ten women talked about staying for their family, five discussed their jobs and livelihoods, five made reference to Parkersburg as "home," and three stayed because it was their birthplace. Hailey described that she stays in Parkersburg because:

"I grew up here. My family is still here. Yes, it was a risk coming back. It did weigh on my mind when we moved back. But we talked about it, and there's risk everywhere. And so you have to weigh risk versus need versus benefit. I love where I grew up. I love my hometown. Is it aggravating sometimes? Yes, it is. But, you know, I wouldn't want to be anywhere else really."

This phenomenon has been studied before with other scholars finding that residents of hazardous communities were unwilling to move despite obvious risk, due to their sense of place (Preston et al. 1983; Bonaiuto et al. 2016; Sullivan and Young 2020). They discovered that there is a 
tendency for those with a strong sense of place to refuse to proactively and retroactively cope with environmental threats (Bonaiuto et al. 2016). These tendencies are present within the women I spoke to, as they all have a strong sense of place yet take part in no retroactive coping mechanisms.

Lived experience of risk associated with water contamination are essential in contributing to a holistic assessment of risk. As such, it is important to consider both local and scientific expertise in risk assessment because of the nuanced nature of local perceptions. As seen from the above findings, perceptions of risk vary from person to person and can affect how someone interacts with contaminated water. For example, several of my interviewees had low risk perception that potentially led to increased C8 exposure, while high risk perception caused some to halt their consumption of tap water altogether. Including such local perceptions of risk can make visible a contaminant that may go otherwise unnoticed.

\subsection{DuPont's Power in the Parkersburg Waterscape}

Unequal power relations between DuPont and Parkersburg residents have caused the perpetuation of water contamination in the Parkersburg region, impacting women's health and well-being and affecting the ways in which women respond (or do not respond) to such contamination. Budds and Hinojosa (2012) described the waterscape perspective as a means to "explore the ways in which flows of water, power, and capital converge to produce uneven socioecological arrangements over space and time" and explained that the characteristics of a waterscape are indicative of broader relations that have shaped its production. A waterscape perspective also raises the question: Who has the power to produce this kind of socionature? Or, who has the power to produce contaminated waterways? and who has the power to act in resistance?

As highlighted by these women's stories, through capitalist development, DuPont has maintained influence within the region which has led to social acceptance of polluted waterways, as residents wish to maintain DuPont's presence due to the jobs they produce. This power has shaped the hydrosocial waterscape of Parkersburg by producing contaminated water that has evaded proper regulation and poisoned citizens with little backlash. Thus, C8 contaminated water is the result of these broader social, political, and economic factors in the Parkersburg region. Further, residents impacted by contamination feel powerless in their ability to resist because of 
the fierce community loyalty and pervasiveness of DuPont's reach. DuPont's power has divided the Parkersburg community, with those maintaining fierce loyalty to DuPont and those who believe DuPont should be held accountable for poisoning the community. In this section, I highlight women's understandings of DuPont's power within the community and later describe how this power has shaped the production of an unequal socionature that negatively impacts women's bodies.

All 18 women that I spoke with made reference to DuPont's economic stronghold and pervasive presence in the region. Several women explained that jobs at Dupont are desired by many in the Parkersburg region due to their high wages and availability to those without a college degree. For example, Rhonda explained:

"DuPont is a big employer around Parkersburg. It has been for years and years. And for a lot of people. When I was growing up, if you had worked at DuPont or one of the big plants around there, you had it made. You were upper class. A rich kid.” This sentiment is shared by Becky, who stated:

"For years the job to have was at DuPont. You worked at DuPont, you had it made. You had a secure job. Good benefits, good pay."

Many women explained that DuPont fostered a sense of loyalty within the region through job growth and community outreach. These "good jobs" cultivated loyalty within their employees and family members, with several women saying, "you don't bite the hand that feeds you." Chelsea described employees' loyalty:

“There's a huge loyalty to DuPont by its employees because it is such a large employer in the area and it provides good well-paying jobs for uneducated people. For example, I've asked my great uncle about it before [who worked at DuPont] and he's like, I shouldn't say anything bad about that company. They gave me 25 good years.' And in the back of my head, I was thinking "you can say something!" like they poisoned the whole city! There's just a lot of loyalty to that company because of the opportunity it provided to people who didn't have education or who wouldn't have had the opportunity otherwise." 
According to the women I interviewed, those who remained loyal to DuPont typically faced no personal health concerns related to C8 and they couldn't fathom that the company they loved so much contaminated an entire community. Natalie articulated this point:

"Our neighbors, our friends, were working at DuPont. And they thought, "What?

DuPont? There's no way DuPont is doing this!' And I think there were a lot of people in the community who were very upset when they thought DuPont was being blamed for something they didn't do. How could this company who is giving money to sports teams and schools and to the hospital and paying good wages for our friends and family and neighbors? How could they possibly have done anything wrong? You don't speak out against them. You don't bite the hand that feeds you. I think it's very hard to think that that company, who took care of so many, and did so many good things, could possibly have hurt us."

In this passage, Natalie touches on DuPont's strong presence in the community. DuPont leveraged its economic influence by sponsoring various sports teams and was "Partners in Education" with several local schools. Even now, their interconnectedness in the community has made it hard for many to accept that they had been poisoning their loved ones.

Not all remained loyal, however, and the community faced a divide between those who continue to support DuPont and those who have spoken out against them. Suzy explained:

"Well, it really split the town. Because a lot of people were saying, 'Oh, well, there's nothing wrong with us. The only thing that's wrong with us is that we need these jobs. We need more jobs like this.' Because there's not a lot of places that you can go without college education. There just were not a lot of jobs like that. So the town was split between some people who had had ill effects that they believed were linked to the poison in the water. And a lot of other people who felt like, 'Oh, suck it up."”

Natalie reaffirms this sentiment by saying:

"It was very hard news to take that our friends and neighbors were working in a place that had very ill effects for some of our community members and continuing effects for those of us living here. So I think that was hard. And I think it's certainly worth 
noting, you know, when you have this giant, which had previously been a very positive force in our community to do that."

Even those who were aware and accepting of DuPont's contamination remained silent out of fear of community backlash and a feeling of powerlessness against DuPont's influence. Many women I spoke to shared that they felt they had no control over their situation and that it simply "is what it is." This tone of acquiesce and apathy was present in conversation with eleven of my participants, with one woman saying:

"I think the more we learn, everybody has just kind of come to terms with it. Like, "Oh, yeah, yeah, we were poisoned.' That is the reality. That's the hand we were dealt."

And another woman stated that people do not speak out against DuPont because:

"We can't change it. There's nothing we can do about it. So we just go along with it and say, 'okay, that's how it is.' That's what I do anyway. Like, 'Oh, it's not affecting me so, I won't care about it right now."”

This apathy towards Dupont was made apparent when I asked the women if they had ever participated in any activism or advocacy against DuPont. Only one of the 18 women I interviewed have taken part in any public facing resistance against DuPont (not including participation in lawsuits) and some even expressed apprehension about activism due to fear of community backlash. Bethany, who received compensation in a lawsuit against DuPont, explained that she has not told anyone about her health concerns or experiences with water contamination because:

"I'm afraid to. I know too many families and stuff that go there and work. That is how they provide for their families. I just try to keep my nose down and go about my day and go to my next doctor's appointment. That's just how I have to live now. And I don't want any trouble. I never wanted any trouble. If I would not have had to go to court, I probably wouldn't have done a thing."

Others reject advocacy because they believe DuPont holds too much power and wealth and because of this, "nothing will ever change." Rhonda echoes this: 
"as long as there's a profit to be made and I mean a big profit to be made, things will never change. They might to a point. They will try to keep [the water] clean. And there will be some people that really try to keep everything clean. But as long as there is that much money involved in this industry, there's going to be some type of pollution in your water."

Seven other women shared similar feelings when asked if they had hope for the future of water quality in Parkersburg. They explained that they had no real hope for change because of DuPont's control over the city. Several women indicated that they feel that the economic power of Dupont will always be valued over people's lives.

Some women attributed individual and community apathy towards DuPont to Appalachian/West Virginian culture. One woman explained that because West Virginia has a “depressed economic situation," people cling to any opportunity they can find, regardless of potential health impacts. In regards to exposure to contaminated water, another woman said, "we allow ourselves to get crapped on repeatedly. That's just part of our culture, I guess.” A third woman, Suzy, connected the Appalachian history of natural resource exploitation to corporate influence in Parkersburg. She said:

"They put those [big corporations] in these places because we're poor and we can be bought off and that's awful. I mean, you have to laugh, or you will cry because those are my people. You know, I love my people but we can be bought off pretty easily. Corporations come there because the land is super cheap. And they know that they can molest it with impunity. They won't be held responsible because all they have to do is toss a little bit of money. And, you know, the Appalachian community is so starved for money and jobs and you know, just for a chance to make a living. That's all you have to do is dangle an opportunity. And it doesn't matter if that opportunity is digging in a coal mine and destroying your lungs or, or pushing out water pollution. They'll do it because they're just starving for an opportunity.

We are some of the poorest, under-educated, economically poor with poor health outcomes, lack of access to medical care..., we just don't have a lot. And we are so overlooked that we're desperate. We are desperate. All you want is an opportunity. So 
you keep your mouth shut and grit your teeth and you bear it. And you hope the opportunity you've been given will provide for your family."

These connections are important to note, as scholars working within a waterscapes perspective argue that holistic accounts of water must include an analysis of historicalgeographical struggles and how complex water-society relationships become embodied in particular landscapes (Karpouzoglou and Vij 2017). In this case, West Virginia's history of natural resource extraction and subsequent environmental degradation has created a landscape and population that has been consistently exploited for capitalist gains. In Parkersburg, there is a clear relationship between water and the broader political economy, as DuPont's economic power has led to contaminated waterways and human bodies. DuPont has shaped the waterscape without impunity and even though it is widely known that DuPont contaminated the local waterways for over 40 years, many maintain loyalty due to their vast community and economic presence. DuPont has not faced serious consequences for many years, which has led to the perpetuation of contamination through unregulated C8 waste disposal and local lawmakers turning a blind eye to these unequal power relations. Although DuPont has lost a number of lawsuits and has paid close to $\$ 400$ million in settlements, this is nowhere near the estimated 1 billion dollars a year they were making at one point from Teflon production (Formuzis 2019). DuPont's continued contamination and lack of accountability and regulation have led to a transformed relationship between women and water in the Parkersburg region. Women face extreme health concerns and have been forced to alter their water procurement strategies and take individual responsibility for securing household water, even though many of these women believe this burden should fall on DuPont's shoulders.

\subsection{Environmental Reproductive Justice and Women's Health in Parkersburg}

DuPont's power has shaped the production of an unequal socionature that negatively impacts women's bodies. For the purposes of this research, a feminist political ecology (FPE) framework is useful in analyzing the everyday dimensions of water inequalities, which are produced by power relations, while research in environmental reproductive justice (ERJ) focuses on the ways that water injustices and hazards can lead to reproductive injustices in a community. My analysis of reproductive health issues in the Parkersburg region contributes to 
bridging these two literatures, as I bring into focus the reproductive health issues resulting from women's daily experiences of water contamination and how these experiences have been shaped by social, economic, and political factors within Parkersburg.

Women's health issues-- including reproductive health problems, autoimmune disorders, and thyroid dysfunction-- were of great concern among my interview participants. Half of the women I spoke with personally experience problems with their reproductive health. This includes six women with polycystic ovarian syndrome (PCOS), five women who are infertile, three with endometriosis, and four having total hysterectomies due to the severity of these various illnesses. In many cases, women experience not just one, but a combination of these reproductive health issues. For example, Lindsey explained:

"I have everything 'women' related. I have polycystic ovarian syndrome.

Endometriosis. I had four different surgeries on my uterus and ovaries and then finally had a hysterectomy two years ago. I feel like that could very well be $\mathrm{C} 8$ related, because there is no family history with any types of fertility issues. I'm not putting everything on C8, but I think because it's all hormone related, I feel like that it's very possible that it's a $\mathrm{C} 8$ issue."

All of the women who reported one of these health conditions believe that $\mathrm{C} 8$ contamination is to blame, whether through direct contact with contaminated water or the possibility of contamination spreading from mother to child.

Bethany is a mother from Porterfield, Ohio, directly across the river from Parkersburg and DuPont, who has had numerous health impacts from C8 contamination. Bethany echoes several sentiments shared by multiple women and her story provides a critical insight into the lived experience of women impacted by water contamination. When asked if she thinks if water contamination impacts women differently than men, Bethany described her experience with multiple reproductive illnesses:

"I do know that there are a lot of women in my area that have had a lot of problems with PCOS and endometriosis, things of that nature. I was diagnosed with endometriosis and PCOS, polycystic ovarian syndrome. So I was diagnosed with a double whammy. Painful periods. Just lots of surgeries to remove cysts or have cysts that would burst inside of you and be excruciating pain. Emergency surgeries. I dealt with that for years. And I just never thought that it was in the cards for me to have a 
child. And lo and behold, I got blessed with my beautiful daughter. But then while I was pregnant, I found out that it was destroying my kidneys. And so, 'yay! you've got this one. But you can't have anymore.' Plus, I had a high-risk pregnancy. And then they said that I wasn't able to have any more children because my kidneys would give out. So I was forced to have a hysterectomy after I had my first child."

Not only is Bethany battling these reproductive health issues, but she also has several autoimmune and thyroid disorders. This is not specific to Bethany, as 12 of 18 of my interviewees have either a thyroid or other autoimmune disorder that they believe is connected to C8 contamination. A range of thyroid diseases were mentioned but most commonly was hyperthyroidism, hypothyroidism, Hashimoto's Thyroiditis, and Grave's Disease. In the medical community, new studies are emerging in regard to PFAS exposure and human impact. As of late, scientists argue there is a strong probability that PFAS chemicals disrupt the thyroid gland and endocrine system, but more studies are needed to make a conclusive remark (Coperchini et al. 2021). Thyroid disorders are more prevalent in women and studies show that abnormalities in thyroid function can have adverse effects on reproductive health including reduced rates of conception, increased early pregnancy loss, and adverse pregnancy and neonatal outcomes (Jefferys et al. 2015).

These reproductive, thyroid, and autoimmune disorders directly impact women's wellbeing and can affect almost every aspect of daily life. Finding proper treatment can be both exhausting and overwhelming, and multiple women discussed the toll treatment has on their bodies and mental health. Allie described her thyroid disorder, called Hashimoto's Thyroiditis:

"Well, because of my Hashimotos, it makes you extremely tired. It makes you not want to get out of bed, like you fight it every day. There are some days where I'm just worn out before I ever get out of bed. So it definitely affects me in terms of my daily function of life. I never know when I wake up in the morning how I'm going to feel or what I'm going to want to do. It can be an extremely overwhelming situation to try to adjust your medication. I instantly know, based on my body now, like when my levels have changed, and I need to go back to the doctor and get it either raised or decreased. Or when I need to take (my medication) because I go on random spurts of, 'I don't want to 
take medicine anymore!' But three weeks later, my hair is falling out and I'm like 'Ugh, I should probably take my medicine because my hair is thinning."'

Bethany also explained the impact of illness on her quality of life:

"It has affected every, every, every piece of my life. I mean, every facet of my life has been touched. I've got more health conditions than any person needs to. And it's just... yeah, I spend most of my time honestly going from one doctor to another. I spend a lot of time doing that. And it gets old, it gets old, but it is just my life and I have to live it. It is unbelievably exhausting. Always getting more medicine, something new will pop up."

Doctors' visits are time consuming and expensive. Multiple surgeries, traveling to and from doctors' appointments, and medical bills add up and create compounding burdens that impact women's mental health on top of their physical problems. Many women discussed actively worrying about the future of their own health and the health of their families and some discussed their concern about unknown $\mathrm{C} 8$ health effects that have yet to be discovered. Bethany depicted this sentiment by saying, "I am worried all the time that something else is going to pop up. Because it's just the older I get, more things are going wrong. I have so many doctors right now. It's ridiculous."

While many of the women trust the C8 science panel and the six confirmed illnesses related to $\mathrm{C} 8$, they worry that there are unknown $\mathrm{C} 8$ health impacts that were unidentified in previous studies or illnesses that were missed. The C8 science panel, which was the health study made to evaluate the effects of $\mathrm{C} 8$ on the population surrounding the chemical plant, only conducted a blood test, and one participant, Cindy, worries that illnesses were missed due to a lack of obtaining complete medical histories. Cindy has done her own extensive research in Parkersburg on C8 contamination and she worries that reproductive health, particularly the number of miscarriages in the area, have been left out of analysis and aren't considered as a major health outcome. She said:

"I think there are some things that perhaps didn't quite fall under what was able to be seen with the $\mathrm{C} 8$ science panel. I believe that the incidence of miscarriages and 
problem pregnancies here, it's so common I think it has to be related. You don't know how many miscarriages a woman's had from a blood test."

Some women also worry that as they get older, they might develop health issues in connection to C8, most notably cancer, as there have been few longitudinal studies in C8 exposure in humans. Nine of the women I talked to discussed the prevalence of cancer in their families and their beliefs in the connectedness to $\mathrm{C} 8$ exposure, even if the specific types of cancer referenced haven't been scientifically proven to be connected. Because cancer is so widespread in the Parkersburg region, many residents conclude that it must be from $\mathrm{C} 8$ exposure. Participants also discussed their worry of possibly becoming infertile or developing thyroid diseases in the future, as well as worries for the future health of their children.

When asked if they believe their health issues are caused by $\mathrm{C} 8$ contamination, every woman discussed how they believe there are no other logical explanations for their diagnoses besides coming in contact with $\mathrm{C} 8$. Some said there were no biological or genetic predispositions for these illnesses, and doctors would explain to them that it must be environmental. For example, Kelsey explained that she never had any health concerns until she moved to the Parkersburg region and drank water from a contaminated well.

Three women believe that their reproductive issues or their families illnesses were genetic, with $\mathrm{C} 8$ contamination or altered genes being passed down from mother to child. One woman discussed her mother's extensive C8 exposure and explained how she believes her sister's, her children's, and her own illnesses stem from her mother's exposure. She explained:

"I think that not only did I get exposed to the water, but I think it somehow mutated with my mom. I think the more she was exposed to it, the more that her genes were. I honestly believe her genes passed it through and affected me as well because not only do I have it, but my sister who didn't even live here has it. She has PCOS and thyroid issues. She has endometriosis. She has the same things I have but she didn't get exposed to the water like I did."

Because $\mathrm{C} 8$ bioaccumulates and never breaks down in the body, several women feel that their eggs may have been contaminated and damaged by C8. Suzy explained C8 impact on women's bodies: 
"I never had kids. I have never been pregnant. And you know, when I was younger, I was not as careful as I am today, but I never got pregnant. I never, never even had a pregnancy scare. So for women, I do think that it is a little bit different. Because, you know, men produce sperm every 90 days. They generate that. Whereas women, we are born with all of the eggs that we will ever have. We're not producing them. So contamination coming in at any time, because you are holding that egg right in you, that doesn't regenerate. It certainly is being contaminated, especially with a cumulative contaminant like C8."

This connection is significant, as other scholars working in ERJ have had similar findings when studying Native American communities impacted by environmental pollution (Cook 2007; Hoover 2018). Katsi Cook (2007) discussed how bioaccumulated contaminants made their way from mother and child in a Mohawk community that experienced polluted waterways and fish, leading to health concerns spread across generations. This kind of injustice deserves to be recognized by the broader public and legal system, but is often made a silent issue due to lack of awareness around reproductive health in general.

Despite these connections that many women have drawn between C8 contamination and problems with their health, reproductive and thyroid issues have largely been excluded from lawsuits against DuPont. Multiple women explained that lawyers turned them down because their illnesses did not fit the tight requirements of litigations at the time, with many lawyers focusing on "higher paying lawsuits that deal with cancer." Allie explained that her lawyers said that she could eventually file a claim and include her various reproductive and thyroid issues, but for now, DuPont was “only paying out for cancers."

This rejection made some women feel powerless about their situation and that they should stop trying to get involved with litigation or activism. Allie was even told by lawyers to shut down her activist Facebook page that was meant to raise awareness about impacts of water contamination. Lawyers told her that it would, "do nothing but create issues, because there was nothing that could have come from it." And that it was, "not going to get her anywhere."

Even the women who have been included in lawsuits were not compensated for their reproductive or thyroid issues at first. To get into the lawsuits, they had to have one of the six 
health outcomes outlined by the C8 science panel. For example, Hailey describes her involvement in a lawsuit against Dupont:

"The deal with the lawsuits was that there were only certain diagnoses that they were going after. And then once you were a part of it, then they will start looking further into all of the different things that you had. So for me, the Irritable Bowel got me in the door. And then once I got in, I was like, 'Look, there are a million other things going on in my life that have been related to this with infertility. I mean, we went to Boston and did clinical trials. We did all kinds of fertility treatments in Morgantown, you know, and just the cost of all of that in itself was significant. So the first settlement was like, nothing. It was like a couple hundred dollars. But then beyond that, in the second part of the lawsuit, were all of these additional things, all these things that crept up. So yeah, it kind of bloomed once you got in the door, but you had to get in the door in order to move forward."

To some, their involvement in the lawsuits was an attempt to fight back against DuPont. Luckily, Bethany was able to recoup some money from a lawsuit due to her Ulcerative Colitis, but for her,

"It was never about the money. I mean, granted, yes. I won't lie. Of course, it was nice. It was great. It was awesome! I am on disability; it was the most money I've ever seen in my entire life. But it really wasn't about the money. With big corporations, it seems like the only time they pay attention is whenever you hit them in their pocketbook. I hate to say that. But I mean, it is. They should just want to keep their community healthy and happy."

For Bethany, suing DuPont was a way to make them pay attention to their community. As discussed above, DuPont has significant economic power in Parkersburg. As Bethany explained, “it's always about the money when it comes to big, big, big, big corporations like that." So for her and others, the only way to get justice for the horrible illnesses DuPont has inflicted upon the community is to make them pay for it. If DuPont is forced to compensate people for the damages done, then they are being held accountable for their actions. These lawsuits are how these women participate in resistance to DuPont's power. 
There are common threads woven throughout each woman's story. However, many women voiced feeling like they were alone in their struggle. Since the C8 controversy has split the town (as discussed above) between those with fierce loyalty to DuPont and those who distrust DuPont, some women feel like they are unable to talk about their experiences due to fear of associated stigma. This silence perpetuates the lack of awareness about thyroid and reproductive health issues caused by DuPont.

It is clear that environmental pollution from the DuPont Washington Works plant has impeded on the reproductive and overall health of multiple women living in the Parkersburg area. At the same time, fear of loss of DuPont's important economic role in the region has resulted in women feeling like they cannot voice their frustrations and seek justice for their reproductive oppression.

Many interviewees noted the gendered inequalities of what health issues are deemed to be important. In discussing gendered impacts of water contamination, one participant, Lindsey said:

"Well, our bodies are different. And so the whole endocrine system and what we're dealing with is not going to be studied because men have the penis, you know? Believe me. If C8 was affecting a man's penis, we would know about it. Like with endometriosis... I spent, before my hysterectomy, one fourth of my life incapacitated with pain. There was a day at school where I was in so much pain, I was crying in fetal position under the desk because I couldn't crawl out of the building. I mean, if there was a disease that affected men like that, it would have been cured 20 years ago. That's just the reality of being a woman and it's bad. And I'm glad that we're at a place where we're saying, 'Hey, this isn't right anymore.' Take care of us too.”

She and others feel that because their health issues are deemed "women's problems," that there is less care and attention paid to them. This unequal power relationship furthers reproductive health issues, as women experiencing these issues feel there is no opportunity to speak out and advocate for reproductive justice.

Multiple women also reflected on their time as children, where gender stereotyping and "housewives" were more common than they are now. It was during the 1950s to the 1990s when DuPont was excessively pumping C8 into local landfills and waterways. Research participants believe that women faced greater threat from water and $\mathrm{C} 8$ contamination because they were the 
ones often held responsible for taking care of the home and therefore more directly in contact with Teflon, which contains C8. Hailey, who is in her 40s, reflected on this time and noted: "I think when I was growing up, a lot more of the women stayed home and raised their families. And so back then, yes water contamination affected women differently than men. Because the women are the ones doing those things... You know, my dad, my uncles, my grandparents, the men... they worked outside. They took care of the garden, they mowed the yard, they took care of the cars, they went to work. Where now, it's much different. You know, our whole world is a little different now. But yeah, I mean, I definitely think back then it certainly affected them more...you know, they're cooking dinner, and they're the ones with their families, they are washing the clothes and washing the dishes."

In the 1950s, DuPont gained FDA approval to start using Teflon, and began producing non-stick pans targeted at the "housewife". Figure 4 depicts a common advertisement used in promoting the new "Happy Pan" Teflon technology and Figure 5 is a screenshot of the "Teflon II/Silverstone/Suprex No-Stick Seal 'Don't Get Stuck'" commercial that ran sometime between 1990 and 1995. 



Figure 4: DuPont's Happy Pan Advertisement from the 1960s. Source: https://commons.wikimedia.org/wiki/File:Happy_Pan_Poster.jpg

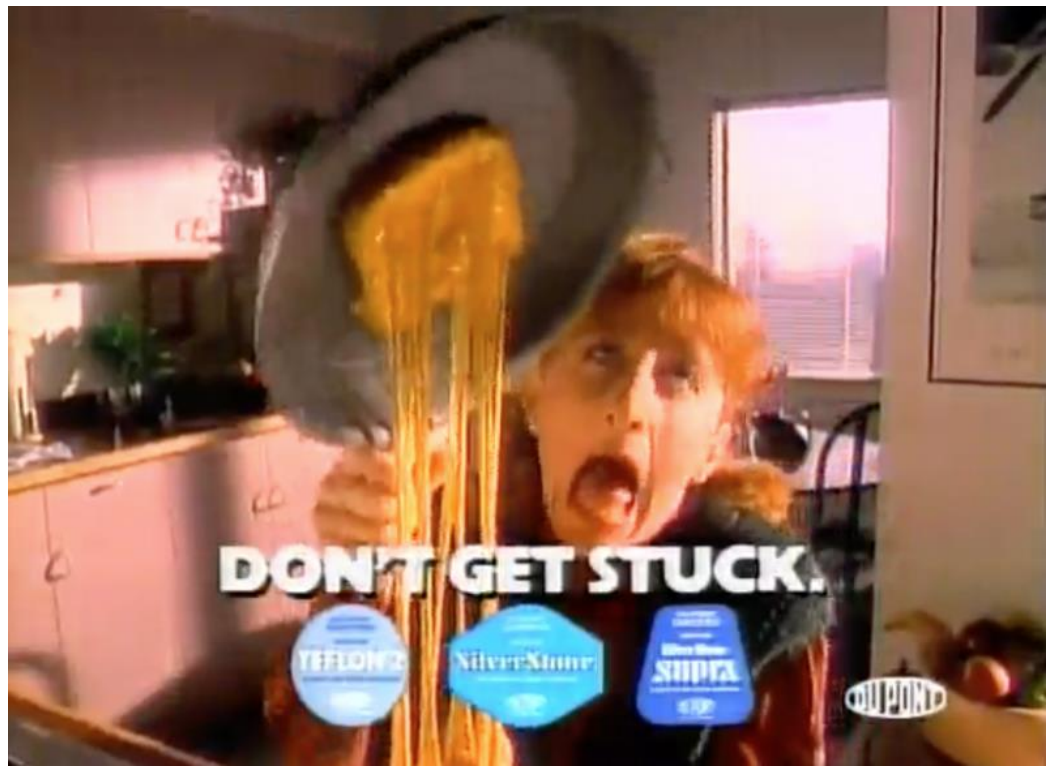

Figure 5: Screenshot from Teflon II/Silverstone/Suprex No-Stick Seal 'Don't Get Stuck' Commercial. Source: https://digital.hagley.org/VID-1995300-B10 
Other gendered differences that women noted involved worry and care. Kelsey said that she felt "women tend to worry more" and are "more concerned" about the health of the family as it relates to access to clean water and Jessie explained that she thinks C8 contamination, "does affect women more than men because women are traditionally the caregivers, so if anyone in the family is ill it is normally the women who bear the brunt of physical nursing and also emotional support." These feelings are important to note as it highlights women's feelings of responsibility for the health of their household. This ties back to feminist political ecology and Rocheleau et al.'s conceptualization of "gendered rights and responsibilities," which encompasses all spaces that are deemed feminine or masculine and how those genders are held responsible for its care. The findings from my research also highlight the "everydayness" (Truelove 2011) of water contamination, as C8 contamination has had drastic impacts on women's bodies and daily life. This research also centers women's perceptions of bodily impacts due to environmental change, which is key to Rocheleau et al.'s emphasis on a political ecology that accounts for gendered environmental knowledges (1996).

Returning to literature in environmental reproductive justice (ERJ), my findings recognize how the social world has profound impacts on women's bodies and health in the Parkersburg region. As noted by ERJ scholar Barbara Gurr, women's bodies experience pollution differently than men's bodies, which creates specific consequences for the community at large related to social and physical reproduction (Gurr 2011; Hoover 2018). This is evident in my findings as several women's reproductive health issues have led to infertility or instances of miscarriages, affecting the physical reproductive abilities of the community itself. Furthermore, social impact of water contamination can be acutely felt by examining a population's health, as described by ERJ scholar Michael Bell (Bell 2009; Gurr 2011; Hoover 2018). Examining this perpetual dialogue between body and environment is key to understanding broader societal and societal impacts of water contamination (Bell 2009).

Most importantly, and as discussed in more detail below, this research contributes at the intersection of feminist political ecology and environmental reproductive justice by examining the unjust physical and mental toll that water contamination has had specifically for women's bodies in Parkersburg. A feminist political ecology framework emphasizes the gendered impacts of water contamination and examines the power dynamics that have shaped women's relationship to water, allowing one to better understand the injustices present in the daily lives of 
these women. In this case, women's drinking water has been contaminated by DuPont and is allowed to continue because of their economic power, which has led to reproductive health issues in the community. As such, this is an environmental reproductive health issue and many of these women worry that they may never find justice. While some women in Parkersburg have been included in lawsuit settlements for other health concerns, reproductive health issues are not included in lawsuits at this time. For justice to be enacted, it is crucial to include women's reproductive health into the conversation around water contamination in Parkersburg, as it is clear that C8 contamination greatly affects many women's health and well-being. After years of pain and neglect, the women of Parkersburg deserve justice and wish that DuPont would be held accountable for their actions.

\subsection{Hope in the "Chemical Valley"}

Despite being continuously contaminated by a pervasive chemical industry and facing numerous health concerns, my participants still hold on to some hope. Lindsey hopes that DuPont will be held accountable for their actions and for justice to be had in her community. Suzy wants to see her friends and neighbors get compensated for the harm inflicted upon them by DuPont. Hailey hopes for transparency as to what pollutants go into local water sources. Sarah and Allie hope for increased awareness and knowledge building about C8 contamination and its long-term effects. Jane asks for increased regulation on chemical pollutants that are allowed into our waterways. Bethany wants her children and grandchildren to be free from contamination. But overall, they all hope for the same thing: clean water. To them, their wishes are simple with one woman explaining that she "would just like to have faith in her fellow man. That honesty and decency would win out over money".

In discussing strategies for change, seven women wish that water quality could be monitored by an outside, third-party source. The trust between women, DuPont, and municipal water departments is virtually nonexistent, and a third-party source could be the only sustainable, trustworthy solution to ensuring that the community has clean water. For example, Hailey echoed this feeling and said:

"I have a lot of trust issues with [DuPont]. I have a lot of trust issues with the Lubeck

Public Service District. And attorneys don't always tell the truth either. So an 
independent review, maybe from someone outside of the valley, who isn't related to DuPont and not being paid off to give an answer... If they came in and said, "Hey, your water safe," then I may feel a little more comfortable."

Other strategies for improvement that women discussed included: widespread filter installation, increased penalties from state and federal agencies against DuPont, individual lawsuits and settlements against DuPont, increased federal regulation and responsibility, and the implementation of the right to water in the United States. The right to water was mentioned by two women, with Chelsea saying:

"I think the government should have to get involved in some way to make sure everyone's getting clean water. I just think it's a human right to have access to clean water and to not have to worry about what's in your water. That's what I hope for our entire community."

This was also reiterated by Natalie:

"Since water is a basic need for all of us, [I hope] that we do get safe and clean water. And I understand that so much of the world does not have safe water, but I would certainly hope that the United States of America could ensure that our citizens have safe drinking water. We can't just give up on water."

Several women discussed their desire for DuPont to take responsibility for contaminating the community's water and to take the proper steps to clean up local waterways. At the same time, some are forgiving of DuPont's past and hope that they remain in the region due to DuPont's economic position. Women's opinions of DuPont are nuanced and sometimes contradictory, as many understand the wrongdoings of DuPont, yet nonetheless, appreciate what they have done for the community economically. For example, Allie stated:

"I would love to see changes be made to our water quality, while not also affecting people's jobs and businesses. I definitely don't want DuPont to shut down by any means, because I know how many people that would affect in our community, but I definitely hope that the changes will continue to be made to make [the water cleaner]." 
And another woman expressed that while C8 contaminated water may have caused her family harm, her and her family harbor no ill feelings towards DuPont. Brittany explained:

"I would never want to sue them. But I do hope that they need to own up to it. But, I mean I'm not angry simply because my family's not angry. And nobody has passed away or had any major birth defects or anything like that in my family. I mean, I have seen documentaries and things like that where people do have that kind of stuff. But maybe if I was impacted a little bit worse, I would feel differently."

In this passage, Brittany makes reference to "documentaries" that have featured Dupont's contamination in Parkersburg, specifically the documentary The Devil We Know and the 2019 "legal thriller," Dark Waters. Nine women mentioned these films and explained that they helped bring awareness to the issue both nationally and locally. While Dark Waters portrays a mostly accurate representation of what truly happened in Parkersburg, several local lawmakers criticized it for taking a "stereotyped look at us as the barefoot hillbillies" (Baucher 2019). Republican delegates even went as far to craft a letter in protest of the showing of the movie in local movie theaters. However, it was not signed by local lawmakers and the film was still shown in theaters, although with limited showings. Regardless, several women found hope after the release of these movies, with Becky explaining:

"I'm hopeful that with what has happened with [the movies], that everybody is paying a lot closer attention to [water contamination in Parkersburg.] I'm hoping that we're monitored more closely. And that forces the water quality to be better."

Building awareness about C8 contamination and the persistent health effects is of great importance to many of the women I spoke with. They hope that increased awareness will bring changes to their water quality and positively impact their health and well-being. They believe that widespread education about the issue could influence residents to organize and resist DuPont's continued contamination. Further, they hope this awareness protects their children and loved ones from experiencing the same hardships they have endured due to DuPont's contaminated water. 


\section{Chapter 5: Discussion and Conclusion}

This research began with three overarching research questions: 1) What are women's understandings of risk associated with household water contamination caused by the Dupont Washington Works plant in Parkersburg, West Virginia?; 2) How do these understandings and experiences of risk impact women's bodies and overall well-being?; And, 3) What are women's hopes for the future of water quality in Parkersburg? These questions were developed through engagement with literature on political ecology, and especially with that of feminist political ecology (FPE) and the political ecology of water. Additionally, my positionality as a woman from Parkersburg informed the creation of my research questions, influenced the manner in which I conducted my research, and helped determine which topics of interest to cover in interviews. Through conducting 18 in-depth interviews with women in the Parkersburg region, and continued engagement with relevant literature, I have answered these three research questions. Each answer is discussed in detail below.

\section{Research Question 1: What are women's understandings of risk related to household water contamination?}

My findings make clear that understandings of risk are complex and differ between each person. They range from no perceived risk to significant risk, with various environmental, physical, and social factors influencing these perceptions. Of note, most of the women that feel significant risk also experience a health condition that they believe is connected to their exposure to $\mathrm{C} 8$ contaminated water. The risk of water contamination, in this sense, is realized in very physical ways for these women, which leaves little room for doubt about C8's potential harm. Of the 14 women I spoke with who have health concerns, especially those with reproductive health issues, all deeply feel there is a correlation with $\mathrm{C} 8$ contamination, even if their issue was not a confirmed diagnosis by the C8 science panel. As Hailey said, "Personally I feel like [the health issues are connected to C8]. I personally do feel like they are because it just seems very odd that people biologically or not biologically within the same half mile radius, that none of us can conceive kids and we've had multiple diagnoses of cancer.” The science panel gathered information via interviews and blood samples, which leaves the possibility of missing diagnoses that were unknown by the patient at the time or not detectable by blood. Unfortunately, lawsuits in the region rely only on the data obtained by the C8 science panel, which excludes illnesses 
like PCOS, endometriosis, and infertility, even though other independent studies have shown instances where women exposed to C8 experience PCOS and endometriosis at higher rates than those who have not (Wang et al. 2019).

Most of the women I interviewed who doubt the risks inherent to exposure have either never personally experienced a health condition commonly related to C8 contamination or do not associate their health issues to exposure. As demonstrated by Sally when she said, "I don't have any health problems. So it's not like, you're gonna drink the water and you're gonna die. I don't think everyone who drinks the water is going to have a problem." As a result, these women tend to doubt the severity of exposure and even if they know C8 runs through their drinking water, they will continue to drink it because they perceive the risk to be low. In this way low perceived risk has the potential to lead to increased contamination, as those with low perceptions of risk do not seek alternative drinking sources to mitigate their exposure. Perceptions of risk are also tied to factors beyond direct health impacts, including trust in water quality reports, media reporting, and relationships with Dupont, as discussed below.

Perceptions of risk are influenced by water quality reports, local news, and popular media. Those who trust in the accuracy of water reports often feel that the risk of exposure is low, as these scientific reports base the safety of water on specific parts-per-trillion guidelines that are determined by the Environmental Protection Agency (EPA). However, there are discrepancies between various standards of "safe" C8 contamination, with the EPA reporting 70 parts-per-trillion as the safety threshold and the US Department of Health and Human Services reporting it almost seven times lower at 11 parts-per-trillion. This uncertainty around safety limits, combined with the dishonest history of water quality information that has been previously disseminated in the Parkersburg region by DuPont, has made many women question the trustworthiness of current and future reports.

There have been several mainstream news agencies, including the Huffington Post, the Washington Post, and the New York Times, that have written articles about C8 contamination in the Parkersburg region (Blake 2015; Williams 2015; Rich 2016). These articles have gained much traction in the region, raising awareness of the issue among some residents and causing tension between groups with differing perceptions of risk. As evident in several Parkersburg Facebook groups that I am a part of, when one of these articles is shared, arguments ensue that 
often result in several people proclaiming their loyalty to DuPont and others expressing anger towards their constant contamination.

There have also been several successful documentaries and a Hollywood produced film that has contributed to increasing awareness of $\mathrm{C} 8$ related risks in the area. This media attention has increased the perception of risk in the community, as these articles and films highlight certain health outcomes that are prevalent in the area. Unfortunately, these stories have neglected the lived experience of women in the region and their reproductive health issues, and instead focused mainly on men who have high-profile illnesses like testicular or kidney cancer. This feeling of neglect was discussed among the women I interviewed, with many feeling that they have been left out of lawsuits due to the "feminine" nature of their health concerns.

Other perceptions of risk are tied to the pervasiveness of DuPont's economic power within the community. As described by several women I interviewed and echoed by other residents in the Parkersburg area, DuPont's ability to sustain the livelihoods of thousands of residents over the past six decades has led to the belief that the benefits of Dupont's presence in the region outweigh the costs. The contamination associated with DuPont's presence in the community is accepted because many people in the region benefit from the jobs that DuPont produces. These jobs are highly sought because they are well-paying, consistent, and require only high school education. DuPont also does various things in the community like building partnerships with schools, teaching children about science, and donating to local charities. For many people, this means that the risks inherent to contamination are not severe enough to cut ties with DuPont (or what is now known as Chemours). Many of the people most loyal to DuPont/Chemours cannot fathom that this company has negatively impacted the community because of their vast presence and job availability. Thus, this loyalty has led to low perceived risk within the Parkersburg region, particularly with those who have personally been employed with DuPont and those with family ties to the company.

Those without loyalty to DuPont may perceive a higher risk related to C8 exposure because they are able to view C8 contamination without a positive bias. People without personal or familial ties to DuPont are more likely to directly connect a negative health outcome with exposure to $\mathrm{C} 8$ contaminated water. Even then, it is hard for people to definitively identify health concerns that are caused by $\mathrm{C} 8$ due to the lack of medical studies on the issue. 
Finally, although each of the 18 women identified various risks associated with contaminated water and living in Parkersburg, they have all chosen to remain in the region due to their strong attachment to and sense of place. Regardless of their perception of significant risk, they remain in Parkersburg because it is their "home." Some women spoke about their familial ties to the area or their contentment with their current livelihoods, with these factors largely contributing to their decision to stay. In this sense, women weighed the costs versus benefits associated with living in the Parkersburg area. For many, suffering from lifelong illnesses due to exposure is not enough to provoke them to leave their home and family. This could be attributed to the fact that they have already had a lifetime of exposure in which $\mathrm{C} 8$ has been bioaccumulating. They are already contaminated and the damage is already done. For some, leaving Parkersburg could mean leaving behind the support system that carries them through their illnesses. For others, financial reasons and costs of living in other cities could prevent them from leaving. Regardless, these women's choice to remain in the region is embedded in their strong sense of place.

\section{Research Question 2: How do these understandings and experiences of risk impact women's bodies and overall well-being?}

The impacts of contamination on women's bodies in the Parkersburg region is immense. This is evidenced by the fact that even when recruiting participants for this project, I was contacted by over 100 women over the course of two days who have experienced health concerns related to $\mathrm{C} 8$ who wanted to be interviewed. Although I was not able to include all of these women into this research project, the 18 women I did talk with told stories about the impact of C8 on women's bodies and echoed the concerns present in the many messages I received. As described by my research participants, experiences of risk mostly manifest in women's bodies through reproductive health, autoimmune, and/or thyroid issues. This is demonstrated by Lindsey when she said, 'I have a thyroid issue. I have everything 'women' related. I have polycystic ovarian syndrome. Endometriosis. I had four different surgeries on my uterus and ovaries and then finally had a hysterectomy two years ago. I feel like that could very well be C8 related".

Women's bodies, and subsequently their children's bodies, bear the brunt of water contamination due to gendered labor differences and related exposure through constant interaction with water via cooking, drinking, bathing, and house chores. Women's well-being is 
further impacted by various factors related to contaminated water including the immense worry that accompanies these health risks, the toll that treatment has on one's mental health, and the stress involved in acquiring water from alternative sources. Women's daily life, as demonstrated by my participants, is altered due to contaminated water and they have had to make adjustments to their daily routine accordingly.

As outlined in the above section 4.4 titled Environmental Reproductive Justice and Women's Health in Parkersburg, bodily impacts have serious consequences for women in the region. These consequences include changes in lifestyle, inability to work, and loss of normal bodily functions like having children. Unfortunately, these women feel alone in their struggle, powerless against DuPont, and excluded from legal and corporate resources. Little attention is paid to women's specific medical conditions, which has led to the lack of legal recourse for these health issues. This exclusion impacts women's well-being, as they are unable to be compensated for the harm they have suffered and are often left out of the narrative surrounding C8 contamination in the region.

On top of this, the women described feeling a sense of responsibility for their households health, a gendered norm that had been ingrained into their consciousness. This sense of responsibility, paired with risks of water contamination, cause women to worry about their households health and well-being. As discussed by several women I spoke with, there is a constant worry about potential health impacts that have yet to be discovered by past medical evaluations of C8 contamination. Women worry about the health and safety of their children, who have bioaccumulated C8 since before birth. This worry inevitably affects the mental health of these women, including through the mental effort of constantly considering ways to avoid contamination all together. This has led women to source water by other means, rather than using water straight from the tap or from their household wells. In some cases, this is not an easy task due to bottled water's long term unaffordability or lack of availability in some areas, and this difficulty can lead to compounding stress. Obtaining water in diverse ways impacts women's daily lives as they often have to spend time, energy, and money to prevent contamination.

DuPont has directly caused harm to these women, yet are left without accountability for their actions. Their economic power, coupled with a loyal following in much of the community, have made women remain publicly silent about their issues due to fear of negative backlash. The "don't bite the hand that feeds you" mentality is pervasive throughout the Parkersburg region, 
which makes those who feel differently further marginalized and apprehensive to speak out against Dupont. The women I spoke with felt like their health concerns were not taken as seriously as other, more highly discussed illnesses like cancer, and therefore they are disregarded when attempting to take legal action. While some women have been included in lawsuits due to other issues, reproductive health is always rejected because of the lack of medical studies that draw a direct correlation between them and C8. This constant rejection, along with the silencing of their stories in the media, have led to decreased willingness to engage in any activism or advocacy against DuPont. If no one is listening to their concerns, why would they bother to personally engage? In the Parkersburg region, women's bodies have been negatively impacted by various illnesses, including: polycystic ovarian syndrome, endometriosis, infertility, autoimmune, hyperthyroidism and hypothyroidism (just to name a few). These illnesses, accompanied by factors like treatment or other unknown C8 health effects, combined with the stress of obtaining clean water, impact their well-being and disrupt their daily lives in ways that make them less likely to be willing or able to participate in action against Dupont.

\section{Research Question 3: What are women's hopes for the future of water quality in Parkersburg?}

This research question, and related interview questions, were challenging to the participants. Although they all had answers to the questions I asked, many lacked confidence in their responses. Despite this, and their general feelings of apathy and powerlessness, these women still hope that the future of water quality in the region will improve. Their hope stems from the desire to live free of contamination and to live in a world where human health is valued more than corporate gains. When women described their hopes, they were often able to come up with concrete solutions that would advance the availability of clean water to everyone, regardless of class, location, gender, and race. These strategies included placing responsibility on individual residents of Parkersburg, on state or federal governments, or on DuPont themselves. Strategies for improvement that women discussed included: widespread filter installation, increased penalties from state and federal agencies against DuPont, individual lawsuits and settlements against DuPont, increased federal regulation and responsibility, and the implementation of the right to water in the United States. However, these solutions to contaminated water are complex, as they involve a range of differing actors and require scarce resources. 
To many women I spoke with, one of their key concerns is elevating awareness and education about $\mathrm{C} 8$ contamination and the persistent health effects. They believe that increased awareness can bring changes to their water quality which could positively impact their health and well-being. Widespread education about the issue could influence residents to organize and resist DuPont's continued contamination, as women believe a hindrance to progress is rooted in lack of awareness. Further, they hope this awareness protects their children and loved ones from experiencing the same hardships they have endured due to DuPont's contaminated water.

Contradictory to their hope and the desire for clean water, when asked if they thought these changes would actually ever be made, most women said no. It seemed as though they were just humoring themselves in their wishes for clean water, like they could speak of their hope while still holding on to the doubt that it will ever be realized. This overall sense of apathy is a result of the broader power relations within the community and is yet another instance where women feel like their opinions or experiences do not matter. They feel that DuPont will remain in power and that the economic benefits it provides to the community will continue to guide decision-making regarding the cleanup of waterways (or lack thereof). Within this reality, why bother imagining a new world that is so far out of reach? This question of hope elicited nuanced answers that do not fully answer the question of women's hopes and visions for the future. Of note, I asked about women's hopes at the end of the interview, after many of them had just told me stories of their illnesses and the power the DuPont holds in the community. The succession of questions could have fostered a sense of hopelessness because of the combined detrimental effects of C8 contamination on their daily lives and DuPont's lack of accountability thus far. This topic is one that is worth exploring further in a future research project.

\subsection{The Political Ecology of C8 contamination in Parkersburg, WV}

My research is situated in the field of political ecology, which helped me frame the examination of the broader power dynamics that have influenced perceptions and experiences of water contamination in the Parkersburg region. As evidenced by my findings, there are unequal costs and benefits associated with environmental pollution in the Parkersburg region, many of which are gendered. DuPont has made billions of dollars from production of C8 and its subsequent products like Teflon, while community members and especially women continue to bear the brunt of the cost through consumption of $\mathrm{C} 8$ contaminated water and the consequential 
impacts on their health and well-being. DuPont's significant economic power and influence is evident from the many people within the town that still hold on to their loyalty despite the factual evidence that DuPont directly poisoned over 100,000 people in the Parkersburg area.

Within political ecology, I contribute to and draw from Feminist Political Ecology (FPE) as I focus on women's voices and their gendered environmental knowledge as it relates to water contamination and related health concerns. FPE focuses on the everyday dimensions of water inequality, and my focus on otherwise mundane water procurement strategies bring the everyday to the forefront, which also shows the extent to which DuPont has altered everyday life for women of the region. Women are particularly marginalized in this story, as their experiences are often excluded from public reports about contamination and they are left out of lawsuits against the corporate giant. This gendered perspective on C8 water contamination has allowed me to uncover a lesser known version of the story - that of reproductive health injustices in the Parkersburg region. This phenomenon, as it relates to Parkersburg and C8, has gone largely unreported in the past and my research fills this gap. A gendered perspective has also allowed me to understand the unequal power dynamics between women and DuPont, as well as gendered perspectives of risk as they relate to experiences of health concerns, including reproductive health injustices.

By explaining how unequal power relations have shaped reproductive health injustices for women in the Parkersburg community, my findings draw an important and under-explored linkage between FPE and environmental reproductive justice (ERJ). Bridging the work on FPE and ERJ is important because the power relations that shape women's everyday environmental experiences are crucial for understanding the causes and consequences of reproductive health issues. In this project, FPE has allowed me to investigate $\mathrm{C} 8$ contamination through a gendered lens, with a focus on the everyday and household scale. The use of an FPE lens led me to uncover specific gendered consequences to $\mathrm{C} 8$ contamination - reproductive health issues which are a result of continued contamination exacerbated by gendered norms that require women's constant contact with contaminated water. I was then able to trace how women's lack of power has manifested through exclusion from litigation and media that has shaped the narrative surrounding Parkersburg and C8. The result is that women have yet to find justice for the reproductive injustices DuPont has caused them. 
Lastly, I use the political ecology of water and the concepts of waterscapes and "modern water" to elucidate my findings related to power and household water security within the Parkersburg region. A waterscape perspective centers a geographically specific experience as it relates to water-society relationships and helps us gain a localized understanding of power relations and how these relations shape water quality in a specific location. The water-society relationship within Parkersburg is heavily influenced by DuPont's pervasive power, as they have altered the waterways and produced a kind of water that has broad societal consequences. An FPE approach can supplement the waterscape approach through centering a gendered perspective on everyday water relations, which results in a deeper understanding of the inner workings of a waterscape with specific attention to gender. My examination of the Parkersburg waterscape revealed widespread water insecurity amongst my participants and brings into question water security more broadly. This widespread water insecurity, which is caused by lack of clean, safe, and reliable water, dispels the myth of modern water as it relates to the global North.

The myth of "modern water" abstracts water from its social, historical, political, and geographic conditions in which it is produced (Linton 2014). In the context of Parkersburg, this abstraction has made contamination and its subsequent negative health effects, and more specifically, women's reproductive health issues, invisible, as the myth of modern water sustains the perception that water is secure, safe, clean, and reliable in the global North. The voices of my research participants illuminate these often silenced stories, bringing much needed awareness to the complex water-society relationships that the myth of modern water obscures.

\section{$\underline{5.2 \text { Conclusion }}$}

It's clear that my participants' understandings of water contamination in the Parkersburg region are nuanced, with each person experiencing contamination, power, and hope in distinct and complicated ways. My participants' perception of risk involving water contamination was influenced by myriad factors including: personal connection to DuPont, severity of health issues, and lack of awareness of the dangers inherent to contamination. One's perception of risk impacted feelings of household water security in the region, as those who felt great risk were forced to alter water procurement strategies, with impacts for their overall well-being. However, despite the nuanced differences in each person's story, I conclude that all 18 of participants 
experience household water insecurity due to their "lack of safe, reliable, sufficient, and affordable water for a thriving life" (Jepson et al. 2017; Meehan et al. 2020).

Women's voices and the specific gendered consequences of C8 contamination have been particularly excluded from public conversation about the topic. This invisibility is maintained by DuPont's power and their economic stronghold within the region which has fostered intense loyalty and split the community in two.

The myth that water is universally accessible, clean, affordable, and trustworthy is based on the experiences of those with power in the global North (Meehan et al. 2020), but this myth does not ring true for many people living in waterscapes of inequality. The women I spoke with in the Parkersburg region have complex understandings of living with the toxicity that comes from long-term exposure to contaminated water. These women do not buy into the myth of modern water but rather articulate deep understandings of the hydrosocial relations that impact their lived experience. This is clearly demonstrated in their discussions of DuPont's power in the region, how this power has impacted their own relationships to water, and how it has transformed water itself. They understand that water is not unaffected by political, historical, and economic factors, but rather it is deeply intertwined with the social world.

As seen from places like Flint, Michigan and Love Canal, New York, there are many communities like Parkersburg within the global North. These places have faced water contamination, bringing widespread recognition to water inequalities that communities face within the United States. Those with power in the global North are not oblivious to the realities of toxic water and they must be held accountable to not perpetuate the myth of modern water, but rather work to create just and equitable access to clean and safe water for all people.

In this research, I have illuminated the voices of 18 women who live in the Parkersburg region in order to gain a deeper understanding of the lived experiences of water contamination and to bring awareness to the injustices these women face. The five key findings that emerged from my research are as follows:

1. The idea of a universal modern water that ensures the equitable distribution of clean, safe, and reliable water in the global North is nothing but a myth in Parkersburg, WV. The Parkersburg waterscape is a prime example of a community in the global North facing widespread household water insecurity due 
to water contamination that hinders their ability to access clean, safe, and reliable drinking water.

2. Perceptions of risk in the Parkersburg community vary between each person ranging from no perceived risk to significant perceived risk, with various environmental, physical, and social factors influencing these perceptions. These factors include personal connection to DuPont, severity of health issues, and lack of awareness of the dangers inherent to contamination. Despite feelings of significant risk, all 18 women remain in the Parkersburg region due to strong sense of place and related attachment.

3. Unequal power relations between DuPont and the community have allowed for the perpetuation of water contamination in the Parkersburg region, which has impacted women's health and well-being and affected the ways in which women respond (or do not respond) to such contamination. These uneven power relations are rooted in DuPont's economic stronghold within the community and a loyal following of past and present workers and family members.

4. Women in Parkersburg are experiencing specific gendered consequences related to $\mathrm{C} 8$ water contamination, namely through reproductive health issues like polycystic ovarian syndrome, endometriosis, and infertility, and thyroid disorders.

5. These women have complex and sometimes contradictory hopes for the future of water in Parkersburg. While women may hold on to some hope that water quality will improve in the future and they provide solutions to ongoing water contamination, they do not have a lot of confidence that it will actually happen due to DuPont's overarching power in the region.

Despite the contradictory nature of women's feelings of hope, many of them propose various strategies for change to have clean water in the future. Among their hopes is the desire to continue to raise awareness about the lived experience of water contamination and beyond this thesis, my participants and I will work together to disseminate their stories to other Parkersburg residents and West Virginia communities more broadly. This will be done collaboratively, with participants' wishes being central in creation of a dissemination strategy. Some preliminary 
thoughts for dissemination include the creation of a website that centers these women's stories and posting subsequent advertisements in local newspapers and news agencies.

In the future, I hope to further this study through investigation of how the intersection of race, class, and gender may converge to create multi-level forms of oppression in the Parkersburg community as it relates to water contamination. This continued work will seek to uncover how these other identities may shape one's perception of risk and if health impacts differ based on different identities. An intersectional perspective can draw attention to the divergence of environmental risk across and within social categories, which can offer a more nuanced understanding of environmental risk and inequity, while also providing the basis for more equitable and community-centered solutions.

It is important to study water-society relationships to gain a deeper understanding of the (re)production of water within a society and how these relationships are indicative of broader power relations within a community. Attention to these relations can lead to people-centered solutions to water contamination and inequalities, which in cases like Parkersburg, could drastically change the daily lives and well-being of women impacted by water contamination. In the future, I hope to see other scholars working at the intersection of FPE and environmental reproductive justice, as I believe the combination of the two fields can lead to a holistic understanding and contextualization of women's everyday lived experience of environmental and reproductive injustices, and how power influences and shapes these phenomena. 


\section{Appendix A: Interview Guide}

Hi! Thanks for taking the time to meet with me today. Before we begin, I just want to quickly talk about the projects goals, confidentiality, and consent. So, as you know, this research project is about women's understandings and experiences of C8 contamination caused by DuPont Washington Works plant in Parkersburg, WV. The interview will take anywhere from 45-90 minutes. Your participation in this project will be kept as confidential as legally possible and no identifying information will ever be made public. Your participation is completely voluntary and you may skip any question you do not wish to answer. Does this sound good? Do I have your permission to record this conversation? (It will not be shared, it's just so I can revisit the conversation).

$\underline{\text { Introduction Questions }}$

I would like to start by asking you a little bit about yourself, just so that I may get to know you better.

1. Where did you grow up?

2. What city or town do you currently live in? How long have you lived there?

a. If they have moved: Why did you move?

3. Why have you decided to settle here?

4. Do you work outside the home? If so, what do you do for employment?

5. What are some of your identities as an individual? (Woman, Appalachian, mother, etc.)

Research Question 1: What are women's understandings of risk associated with household water contamination caused by the Dupont Washington Works plant in Parkersburg, West Virginia?

Next, I would like to ask you some questions related to water contamination and related risks.

1. What is the source of your household's drinking water?

a. Do you use tap water?

b. Do you source your water from somewhere besides the tap?

2. Is your water source reliable?

3. Do you consider the water that comes from your tap to be clean and safe?

4. If you have another source of water, do you consider it to be clean and safe?

5. Has your household experienced contaminated water?

a. If so, how can you tell it is contaminated (i.e. discolored or foamy water, smell, or reported data)?

b. How frequently does this occur and how long does it last when it happens?

6. Do you think you or your family's health has been or is at risk due to water contamination?

a. What risks do you think are associated with consuming contaminated water?

b. Which of these risks worry you the most and why?

7. Do you think you feel the same level of risk or awareness as others in the Parkersburg area?

8. What do you think is the source of your household's water contamination? 
9. Do you receive information about water quality from any external sources? If so, what are the sources and do you think they provide you with accurate information about water quality in your area?

Research Question 2 : How do these understandings and experiences of risk impact women's bodies and overall well-being?

Next, I would like to ask you some questions about how these risks impact your health and wellbeing in your day-to-day life.

1. Have you experienced any health concerns related to water contamination?

2. Has water contamination impacted your day-to-day life and everyday tasks (like cooking, bathing, procuring water) in particular ways?

3. Have you adjusted how or where you live, work, or spend free time as a result of the risks associated with water contamination?

a. If so, describe how.

4. Has water contamination / health issues affected your level of happiness, comfort, or quality of life?

5. Do you think the risks of water contamination affect women differently than men?

a. If so, how? If not, Why?

6. Do you think these risks should be regulated or mitigated by Dupont? If so, how? If not, why?

a. Why do you think people haven't spoken out against DuPont?

7. Do you think these risks should be regulated or mitigated by local and/or state governments? If so, how? If not, why?

8. Do you think DuPont/ state and local government should be responsible for ensuring clean water?

9. Do you think anyone else is responsible for regulating or mitigating risks?

Research Question 3 : What are women's hope for the future of water quality in Parkersburg?

Finally, I want to ask you some questions about how water contamination impacts your visions and hopes for the future of Parkersburg.

1. Why do you stay in Parkersburg, despite the risks of water contamination?

2. Do you plan to continue living here for the foreseeable future? Why or why not?

3. What do you hope will change about water quality in the future?

4. Who do you think is or should be responsible for making these changes?

5. What do you think it would take for these changes to be made?

6. Do you have hope that such changes will be made?

7. Do you think DuPont/Chemours is still contaminating water?

8. Do you plan to engage in any efforts to enact such changes? Why or why not?

Is there anything else you think I should know related to this topic? 
Thank you very much for taking the time to talk to me today.... Detail next steps...

\section{Appendix B: Data Analysis Tools}

1.) Disrupting the Myth of Modern Water through Examination of the Parkersburg Waterscape

a.) Main Code Group: Water

i.) Sub-Codes

(1) Water (Unsafe, Unclean, Unreliable)

(2) Water (Safe, Clean, Reliable)

(3) Modern Water

(4) Water Senses (Taste, Smell, Sight)

(5) Water Contamination

(6) Water Reports

(7) Source (Bottled, Filtered, Well)

(8) Water Infrastructure

2.) Perceptions of Risk in a Contaminated Community

a.) Main Code Group: Risk

i.) Sub- Codes

(1) Risk (Significant)

(2) Risk (Normalized, Habitual)

(3) Risk (Priorities)

(4) Risk (For Children)

(5) Risk (Not that bad)

(6) Risk (None)

(7) Risk (Lack of Scientific Understanding)

3.) Attachment to and Sense of Place (Included in above section)

a.) Main Code Group: Place

i.) Sub-Codes

(1) Place (Money, Birthplace, Family, Job)

(2) Place (Home)

(3) Culture

4.) DuPont's Power in the Parkersburg Waterscape

a.) Main Code Group: Power

i.) Sub-Codes

(1) DuPont (Economic Power)

(a) Distrust

(2) DuPont (Fear, Loyalty)

(3) Power

(4) Acquiescence / Apathy

(a) "It is what it is" 
(b) "Don't bite the hand that feeds you"

(c) "No hope for real change"

5.) Environmental Reproductive Justice and Women's Health in Parkersburg

a.) Main Code Group: Health

i.) Sub-Codes

(1) Reproductive Health

(2) Endometriosis

(3) Infertility

(4) PCOS

(5) Hysterectomy

ii.) Thyroid Disease

(1) Hyperthyroidism

(2) Hypothyroidism

(3) General Thyroid

(4) Hashimoto's Thyroiditis

(5) Graves' Disease

iii.) Well-being

(1) Treatment

(2) Mental Health

(3) Worry

(a) Unknown C8 Health Effects

(b) Genetic

iv.) Main Code Group: Gender

6.) Hope in the "Chemical Valley"

a.) Main Code Group: Health

b.) Sub-Codes

i.) Hope (Awareness, Honesty, Transparency, Accountability, Youth)

ii.) Hope (Clean Water)

iii.) Strategies for Change

(1) Outside Source

iv.) Regulation

v.) Activism

(List of main code groups and their sub-categorized codes as they pertain to sections to Chapter 4: Findings.) 


\begin{tabular}{|c|c|c|c|c|c|c|c|c|c|}
\hline Alias & PCOS & Hysterectomy & $\begin{array}{l}\text { Uterine } \\
\text { Cancer }\end{array}$ & Endo & Infertility & $\begin{array}{l}\text { Hyper- } \\
\text { thyroidism / } \\
\text { Graves }\end{array}$ & $\begin{array}{l}\text { Hypo- } \\
\text { thyroidism / } \\
\text { Hashimotos }\end{array}$ & $\begin{array}{l}\text { Other Thyroid / } \\
\text { Autoimmune }\end{array}$ & $\begin{array}{l}\text { Cancer } \\
\text { in } \\
\text { Family }\end{array}$ \\
\hline Kelsey & & 1 & 1 & & & & & & 1 \\
\hline Anna & 1 & 1 & & & & & & & 1 \\
\hline Sarah & 1 & & & & & 1 & & 1 & 1 \\
\hline \multicolumn{10}{|l|}{ Sally } \\
\hline Jane & & & & & & & 1 & & \\
\hline Jessie & 1 & & & & & & 1 & & 1 \\
\hline Cindy & & & & & & & & 1 & \\
\hline \multicolumn{10}{|l|}{ Becky } \\
\hline Lindsey & 1 & 1 & & 1 & 1 & & & 1 & 1 \\
\hline Suzy & & & & & 1 & & & & 1 \\
\hline Bethany & 1 & 1 & & 1 & 1 & & & 1 & \\
\hline Chelsea & & & & & & 1 & & & 1 \\
\hline Brittany & & & & & & & & 1 & 1 \\
\hline \multicolumn{10}{|l|}{ Natalie } \\
\hline Kaitlyn & & & & & & & & 1 & \\
\hline Rhonda & & & & & & 1 & & & \\
\hline Hailey & & & & & 1 & & 1 & & 1 \\
\hline Allie & 1 & & & 1 & 1 & & 1 & & \\
\hline
\end{tabular}

(Spreadsheet used to analyze findings on Women's Health) 


\section{Works Cited}

Allaire, M., H. Wu, and U. Lall. 2018. National trends in drinking water quality violations. Proceedings of the National Academy of Sciences 115 (9):2078-2083.

Allen, E. 2019. Study Finds West Virginia Counties Among 'Worst in Nation' For Drinking Water Violations. WV Public Broadcasting. www.wvpublic.org/news/2019-09-24/ studyfinds-west-virginia-counties-among-worst-in-nation-for-drinking-water-violations (last accessed 8 April 2021).

Archibald, M. M., R. C. Ambagtsheer, M. G. Casey, and M. Lawless. 2019. Using Zoom Videoconferencing for Qualitative Data Collection: Perceptions and Experiences of Researchers and Participants. International Journal of Qualitative Methods 18:160940691987459.

Auyero, J., and D.A. Swistun. 2009. Flammable: Environmental suffering in an Argentine shantytown. New York, NY: Oxford University Press.

Bakker, K. 2003. Archipelagos and networks: Urban water privatization in the South. Geographical Journal 169(4): 328-341.

Baucher, T. 2019. 'Dark Waters' movie criticized by W. Va. lawmakers. WTAP News. https://www.wtap.com/content/news/Dark-Waters-movie-discussed-locally-565119912.html (last accessed 27 June 2021).

Baxter, J. and J. Eyles. 1997. Evaluating Qualitative Research in Social Geography: Establishing 'Rigour' in Interview Analysis. Transactions of the Institute of British Geographers 22: 505525.

Baxter, J. and J. Eyles. 1999. The Utility of In-Depth Interviews for Studying the Meaning of Environmental Risk. The Professional Geographer 51(2): 307-320.

Baxter, J., J. Eyles, and S. Elliott. 1999. 'something happened': the relevance of the risk society for describing the siting process for a municipal landfill. Geografiska Annaler: Series B, Human Geography 81 (2):91-109.

Bebbington, A. 1999. Capitals and Capabilities: A Framework for Analyzing Peasant Viability, Rural Livelihoods and Poverty. World Development 27 (12):2021-2044.

Beck, U. 1992. Risk Society: Towards a New Modernity. London: Sage. 
Bennett, P. 1999. Governing environmental risk: regulation, insurance and moral economy. Progress in Human Geography 23 (2):189-208.

Bell, M. 2009. An Invitation to Environmental Sociology. Thousand Oaks, CA: Pine Forge Press

Bell, S. E. 2013. Our Roots Run Deep as Ironweed: Appalachian women and the fight for environmental justice. Urbana, Chicago, and Springfield: University of Illinois Press.

Bennett, P. 1999. Governing environmental risk: regulation, insurance and moral economy. Progress in Human Geography 23 (2):189-208.

Bickerstaff, K., and G. Walker. 2003. The place(s) of matter: matter out of place - public understandings of air pollution. Progress in Human Geography 27 (1):45-67.

Bilott, R., and T. Shroder. 2019. Exposure: poisoned water, corporate greed, and one lawyer's twenty-year battle against Dupont First Atria Books. New York: Atria Books.

Blaikie, P., and H. Brookefield. 1987. Land Degradation and Society. London: Routledge.

Blake, M. A Toxic Chemical Ruined The Lives Of These People — And It's Probably In Your Blood. The Huffington Post. https://highline.huffingtonpost.com/articles/en/welcome-tobeautiful-parkersburg/ (last accessed 16 October 2020).

Bonaiuto, M., S. Alves, S. De Dominicis, and I. Petruccelli. 2016. Place attachment and natural hazard risk: Research review and agenda. Journal of Environmental Psychology 48: 33-53.

Browne, K. 2005. Snowball sampling: using social networks to research non-heterosexual women. International Journal of Social Research Methodology 8 (1):47-60.

Brulle, R. J., and D. N. Pellow. 2006. ENVIRONMENTAL JUSTICE: Human Health and Environmental Inequalities. Annual Review of Public Health 27 (1):103-124.

Bryant, R.L. and S. Bailey. 1997. Third World Political Ecology. London: Routledge.

Budds, J. 2004. Power, Nature and Neoliberalism: The Political Ecology of Water in Chile. Singapore Journal of Tropical Geography 25 (3):322-342.

Budds, J. 2008. Whose scarcity? The hydrosocial cycle and the changing waterscape of La Ligua river basin, Chile. In Goodman, M.; Boykoff, M. and Evered, K. (Eds), Contentious geographies: Environment, meaning, scale, pp. 59-68. Aldershot, UK: Ashgate.

Budds, J., and L. Hinojosa. 2012. Restructuring and Rescaling Water Governance in Mining Contexts: The Co-Production of Waterscapes in Peru. 5 (1):19.

Cahill, C. 2007. Repositioning Ethical Commitments: Participatory Action Research as a Relational Praxis of Social Change. ACME 6(3): 360-373. 
Caretta, M. A., and M .A. Pérez. 2019. When Participants Do Not Agree: Member Checking and Challenges to Epistemic Authority in Participatory Research. Field Methods, 31(4), 359-374.

Caretta, M. A., and Y. Riaño. 2016. Feminist participatory methodologies in geography: creating spaces of inclusion. Qualitative Research, 16(3): 258-266.

Caretta, M. A., S, Zaragocin, B. Turley, and K. T. Orellana. 2020. Women's organizing against extractivism: towards a decolonial multi-sited analysis. Human Geography 13(1): 49-59.doi: $10.1177 / 1942778620910898$

Castree, N. 2001. 'Socializing nature: Theory, practice, and politics', in N. Castree \& B. Braun (eds.), Social Nature: Theory, Practice, and Politics Oxford: Blackwell, 1-21.

CDC. 2017. Perfluorooctanoic Acid (PFOA) Factsheet | National Biomonitoring Program $\mid C D C$. https://www.cdc.gov/biomonitoring/PFOA_FactSheet.html (last accessed 16 October 2020).

Chaskin, R. J. 2008. Resilience, Community, and Resilient Communities: Conditioning Contexts and Collective Action. Child Care in Practice 14 (1):65-74.

Checker, M. 2007. "But I Know It's True”: Environmental Risk Assessment, Justice, and Anthropology. Human Organization 66 (2):112-124.

Cho, J., and A. Trent. 2006. Validity in qualitative research revisited. Qualitative Research, 6(3) 319-340.

Cook, K. 2007. "Environmental Justice: Woman Is the First Environment." In Reproductive Justice Briefing Book; A Primer on Reproductive Justice and Social Change, edited by S. Song, 62-63. https://www.law.berkeley.edu/php-programs/courses/fileDL.php?fID=4051

Cope, M. 2010. A history of qualitative research in geography. The SAGE handbook of qualitative geography, 22-45.

Cope, M. 2019. Transcribing, Coding, and Analyzing Qualitative Data. In: Kobayashi, A. (Ed.), International Encyclopedia of Human Geography, $2^{\text {nd }}$ edition. Vol. 13, Elsevier, 357-362.

Coperchini, F., L. Croce, G. Ricci, F. Magri, M. Rotondi, M. Imbriani, and L. Chiovato. 2021. Thyroid Disrupting Effects of Old and New Generation PFAS. Frontiers in Endocrinology 11:612320.

Cordner, A., V. Y. De La Rosa, L. A. Schaider, R. A. Rudel, L. Richter, and P. Brown. 2019. Guideline levels for PFOA and PFOS in drinking water: the role of scientific uncertainty, risk assessment decisions, and social factors. Journal of Exposure Science \& Environmental Epidemiology 29 (2):157-171.

Coyne, C. 2019. Dangerous PFAS chemicals are unmonitored in WV's waters. A 2020 bill aims to change that. WV Gazette. https://www.wvgazettemail.com/news/health/dangerous-pfas- 
chemicals-are-unmonitored-in-wvs-waters-a-2020-bill-aims-to-change-

that/article_f0b92ec6-7412-5c4e-a139-200c858eb3d4.html (last accessed: 27 June 2021)

Creswell, J. W., and J. D. Creswell. 2017. Research Design: Qualitative, Quantitative, and Mixed Methods Approaches. SAGE Publications, Inc.

Cresswell, J. W., and V. L. Plano Clark. 2011. Designing and conducting mixed method research. 2nd Sage. Thousand Oaks, CA

Deggs, D. M., and F. Hernandez. 2018. Enhancing the Value of Qualitative Field Notes through Purposeful Reflection. The Qualitative Report 23 (10):2552.

Develop Wood County. 2020. Chemours Washington Works. https://developwoodcountywv.com/wp-content/uploads/2017/04/20170215_16-BID1019_ChemoursWashingtonWorksBrochure_Client.pdf (last accessed 25 April 2021).

DuPont. 2010. DuPont GenX Processing Aid for Making Fluoropolymer Resins: Setting a New Industry Standard for Sustainable Replacement Technology. https://bladenonline.com/wpcontent/uploads/2017/06/Chemours_GenX_Brochure_Final_07July2010.pdf (last accessed 23 July 2021).

Ekers, M., and A. Loftus. 2008. The Power of Water: Developing Dialogues between Foucault and Gramsci. Environment and Planning D: Society and Space 26 (4):698-718.

Environmental Working Group. 2021. Mapping the PFAS Contamination Crisis: New Data Show 2,337 Sites in 49 States. Environmental Working Group. https://www.ewg.org/interactive-maps/pfas_contamination/ (last accessed 2 June 2021).

Elmhirst, R. 2011. Introducing new feminist political ecologies. Geoforum 42 (2):129-132.

Ellis, F. 2000. Rural livelihoods and diversity in developing countries. Oxford university press.

England, K. V. L. 1994. Getting Personal: Reflexivity, Positionality, and Feminist Research. The Professional Geographer 46 (1):80-89.

Formuzis, A. 2019. DuPont made billions polluting tap water with PFAS; will now make more cleaning it up. EWG News. https://pfascentral.org/news/dupont-made-billions-polluting-tapwater-with-pfas-will-now-make-more-cleaning-it-up (last accessed 27 June 2021).

Friese, S., 2019. Qualitative data analysis with ATLAS. ti. Sage.

Graham, S., anliked Marvin, Simon. 2002. Splintering Urbanism: Networked Infrastructures, Technological Mobilities and the Urban Condition 1st ed. Routledge. https://www.taylorfrancis.com/books/9780203452202 (last accessed 27 June 2021). 
Grigg, N. 2019. Aging water infrastructure in the United States. In P. Juuti, H. Mattila, R. Rajala, K. Schwartz, \& C. Staddon (Eds.), Resilient Water Services and Systems: The Foundation of Well-being, pp. 31-46. London: IWA Publishing.

Guest, G., K. MacQueen, and E. Namey. 2012. Applied Thematic Analysis. 2455 Teller Road, Thousand Oaks California 91320 United States: SAGE Publications, Inc. http://methods.sagepub.com/book/applied-thematic-analysis (last accessed 27 June 2021).

Guillemin, M., and L. Gillam. 2004. Ethics, Reflexivity, and "Ethically Important Moments" in Research. Qualitative Inquiry 10 (2):261-280.

Gurr, B. 2011. Complex Intersections: Reproductive Justice and Native American Women: Complex Intersections. Sociology Compass 5 (8):721-735.

Haraway, D. J. 1988. Situated knowledges: The science question in feminism and the privilege of partial perspective. Feminist Studies 14(3):575-599.

Harvey, D., and R. Williams. 1995. Militant Particularism and Global Ambition: The Conceptual Politics of Place, Space, and Environment in the Work of Raymond Williams. Social Text (42):69-98.

Hesse-Biber, S. 2010. Qualitative Approaches to Mixed Methods Practice. Qualitative Inquiry 16(6): 455-468. doi: 10.1177/1077800410364611

Hiemstra, N., and E. Billo. 2017. Introduction to Focus Section: Feminist Research and Knowledge Production in Geography. The Professional Geographer 69 (2):284-290.

Hoover, E. 2018. Environmental reproductive justice: intersections in an American Indian community impacted by environmental contamination. Environmental Sociology 4 (1):8-21.

Howe, K. R. 2004. A critique of experimentalism. Qualitative Inquiry 10(1): 42-61.

Jefferys, A., M. Vanderpump, and E. Yasmin. 2015. Thyroid dysfunction and reproductive health. The Obstetrician \& Gynaecologist 17 (1):39-45.

Jepson, W. E., A. Wutich, S. M. Colllins, G. O. Boateng, and S. L. Young. 2017. Progress in household water insecurity metrics: a cross-disciplinary approach: Progress in household water insecurity metrics. Wiley Interdisciplinary Reviews: Water 4 (3):e1214.

Karpouzoglou, T., and S. Vij. 2017. Waterscape: a perspective for understanding the contested geography of water: Waterscape. Wiley Interdisciplinary Reviews: Water 4 (3):e1210

Kearns, R. and Andrews, G. 2010. "Geographies of wellbeing”. In The Sage handbook of social geographies, Edited by: Smith, S., Marston, S., Pain, R. and Jones, J. P. III. 309-28. London: Sage. 
Keen, S., \& Todres, L. 2007. Strategies for disseminating qualitative research findings: Three exemplars. In Forum: Qualitative Social Research (Vol. 8, No. 3, pp. Art-17). Bournemouth University, Fern Barrow, Poole, Dorset, BH12 5BB, UK.

Kenney, E. L., J. G. Daly, R. M. Lee, R. S. Mozaffarian, K. Walsh, J. Carter, and S. L. Gortmaker. 2019. Providing Students with Adequate School Drinking Water Access in an Era of Aging Infrastructure: A Mixed Methods Investigation. International Journal of Environmental Research and Public Health 17 (1):62.

Kooy, M. 2014. Developing Informality: The Production of Jakarta's Urban Waterscape. 7 (1):19.

Langford, I. H. 2002. An existential approach to risk perception. Risk Analysis 22: 101-120.

Liddell, J. L., and S. G. Kington. 2021. "Something Was Attacking Them and Their Reproductive Organs": Environmental Reproductive Justice in an Indigenous Tribe in the United States Gulf Coast. International Journal of Environmental Research and Public Health 18 (2):666.

Linton, J., 2010. What is water?: The history of a modern abstraction. UBC press.

Linton, J. 2014. Modern water and its discontents: a history of hydrosocial renewal: Modern water and its discontents. Wiley Interdisciplinary Reviews: Water 1 (1):111-120

Linton, J., and J. Budds. 2014. The hydrosocial cycle: Defining and mobilizing a relationaldialectical approach to water. Geoforum 57:170-180.

Loftus, A. 2009. Rethinking Political Ecologies of Water. Third World Quarterly 30 (5):953968.

Long, T., and M. Johnson. 2000. Rigour, reliability and validity in qualitative research. Clinical Effectiveness in Nursing 4 (1):30-37.

Longhurst, R. 2003. Semi-structured interviews and focus groups. Key Methods in Geography 3(2):143-156.

Mabry, L. 2012. Case Study in Social Research. In Alasuutari, P., Bickman, L., \& Brannen, J. (Eds)., SAGE Handbook of Social Research Methods (pp. 214-277), SAGE Publications Ltd: London.

MacKenzie, C. A., J. Christensen, and S. Turner. 2015. Advocating beyond the academy: dilemmas of communicating relevant research results. Qualitative Research 15 (1):105-121.

Maynard, M., and J. Purvis. 2013. Researching Women's Lives From A Feminist Perspective. Routledge. 
McCulligh, C., L. Arellano-García, and D. Casas-Beltrán. 2020. Unsafe waters: the hydrosocial cycle of drinking water in Western Mexico. Local Environment 25 (8):576-596.

Meehan, K. M. 2014. Tool-power: Water infrastructure as wellsprings of state power. Geoforum 57:215-224.

Meehan, K., J. R. Jurjevich, N. M. J. W. Chun, and J. Sherrill. 2020. Geographies of insecure water access and the housing-water nexus in US cities. Proceedings of the National Academy of Sciences 117 (46):28700-28707.

Meehan, K., W. Jepson, L. M. Harris, A. Wutich, M. Beresford, A. Fencl, J. London, G. Pierce, L. Radonic, C. Wells, N. J. Wilson, E. A. Adams, R. Arsenault, A. Brewis, V. Harrington, Y. Lambrinidou, D. McGregor, R. Patrick, B. Pauli, A. L. Pearson, S. Shah, D. Splichalova, C. Workman, and S. Young. 2020. Exposing the myths of household water insecurity in the global north: A critical review. WIREs Water 7 (6):e1486.

Mehta, L. 2014. Water and Human Development. World Development 59:59-69.

Nicole, W. 2013. PFOA and Cancer in a Highly Exposed Community: New Findings from the C8 Science Panel. Environmental Health Perspectives 121 (11-12):A340.

Oberhauser, A. M., J. L. Mandel, and H. M. Hapke. 2004. Gendered livelihoods in diverse global contexts: an introduction. Gender, Place \& Culture 11 (2):205-208.

Palinkas, L. A., S. M. Horwitz, C. A. Green, J. P. Wisdom, N. Duan, and K. Hoagwood. 2015. Purposeful sampling for qualitative data collection and analysis in mixed method implementation research. Administration and policy in mental health 42 (5):533.

Pearson, T. W. 2020. Communities Grapple with Exposure to 'Forever Chemicals."'SAPIENS, July 31. https://www.sapiens.org/culture/pfas-contamination/.

Peet, R. and Watts, M., editors 1996. Liberation ecologies: environment, development, social movements. London: Routledge.

PFAS Project. 2020. Studying Social, Scientific, and Political Factors of Per- and Polyfluoroalkyl Substances. Social Science Environmental Health Research Institute, Northeastern University. https://pfasproject.com/ (las accessed 27 June 2021).

Preston, V., S. M. Taylor, and D. C. Hodge. 1983. Adjustment to Natural and Technological Hazards: A Study of an Urban Residential Community. Environment and Behavior 15 (2):143-164.

Price, K. 2010. What is Reproductive Justice? How Women of Color Activists Are Redefining the Pro-Choice Paradigm. Meridians 10 (2):42-65. 
Renfrew, D. and T.W. Pearson. 2021. "The Social Life of the 'Forever Chemical': PFAS

Pollution Legacies and Toxic Events," Environment and Society: Advances in Research 12, Forthcoming

Rich, N. 2016. The Lawyer Who Became DuPont's Worst Nightmare (Published 2016). The New York Times https://www.nytimes.com/2016/01/10/magazine/the-lawyer-who-becameduponts-worst-nightmare.html (last accessed 16 October 2020).

Richter, L., A. Cordner, and P. Brown. 2018. Non-stick science: Sixty years of research and (in)action on fluorinated compounds. Social Studies of Science 48 (5):691-714.

Robbins, P. 2004. Political Ecology: A critical introduction. Malden, MA: Blackwell Publishers.

Rocheleau, D., B. Thomas-Slayter, and E. Wangari. 1996. Feminist Political Ecology. New York: Routledge

Schmidt, J. J., and D. Shrubsole. 2013. Modern Water Ethics: Implications for Shared Governance. Environmental Values 22 (3):359-379.

Stall, S., and R. Stoecker. 1998. Community Organizing Or Organizing Community?: Gender and the Crafts of Empowerment. Gender \& Society 12 (6):729-756.

Steingraber, S. 2010. Living downstream: an ecologist's personal investigation of cancer and the environment 2nd ed., 1st Da Capo Press ed. Cambridge, MA: Da Capo Press.

Sullivan, D., and I. F. Young. 2020. Place Attachment Style as a Predictor of Responses to the Environmental Threat of Water Contamination. Environment and Behavior 52 (1):3-32.

Sultana, F. 2009. Fluid lives: Subjectivities, gender and water in rural Bangladesh. Gender, Place, and Culture 16(4):427-444.

Sultana, F. 2011. Suffering for water, suffering from water: Emotional geographies of resource access, control and conflict. Geoforum 42 (2):163-172.

Swyngedouw, E. 1999. Modernity and Hybridity: Nature, Regeneracionismo, and the Production of the Spanish Waterscape, 1890-1930. Annals of the Association of American Geographers 89 (3):443-465.

Tartaglia, S., E. Conte, C. Rollero, and N. de Piccoli. 2018. The influence of coping strategies on quality of life in a community facing environmental and economic threats. Journal of Community Psychology 46: 251-260.

Tatar, M., T. Baucher, and A. Press. Update: EPA sends violation notice to Chemours on GenX contamination. WTAP News. https://www.wtap.com/content/news/New-report-shows-GenXnot-found-in-treated-water--480872601.html (last accessed 16 October 2020). 
Taylor, J. 2011. "The Intimate Insider: Negotiating the Ethics of Friendship When Doing Insider Research." Qualitative Research 11: 3-22.

Truelove, Y. 2011. (Re-)Conceptualizing water inequality in Delhi, India through a feminist political ecology framework. Geoforum 42 (2):143-152.

U.S. Census Bureau. 2019. QuickFacts Parkersburg City, West Virginia. https://www.census.gov/quickfacts/fact/table/parkersburgcitywestvirginia/PST0452 19 (last accessed 25 April 2021).

USEPA. Environmental Justice. Available online: https://www.epa.gov/environmentaljustice (last accessed 25 April 2021).

USEPA. 2018. Fact Sheet: Draft Toxicity Assessments for GenX Chemicals and PFBS. https://www.epa.gov/sites/production/files/2018-11/documents/factsheet_pfbs-genxtoxicity values 11.14.2018.pdf. (last accessed 27 June 2021).

USEPA. 2021. Drinking Water Health Advisories for PFOA and PFOS. https://www.epa.gov/ground-water-and-drinking-water/drinking-water-health-advisoriespfoa-and-pfos (last accessed 2 June 2021).

U.S. National Toxicity Program. 2016. NTP Research Program on Chemicals Spilled into the Elk River in West Virginia. https://ntp.niehs.nih.gov/ntp/research/areas/wvspill/wv_finalupdate_july2016_508.pdf (last accessed 27 June 2021).

Volcovici, V. 2018. EPA-recommended chemicals levels in water too high: U.S. report. Reuters. https://www.reuters.com/article/us-usa-epa-chemicals/epa-recommended-chemicals-levelsin-water-too-high-u-s-report-idUSKBN1JG38Z (last accessed 2 June 2021).

Wakefield, S. E. L., S. J. Elliott, D. C. Cole, and J. D. Eyles. 2001. Environmental risk and (re)action: air quality, health, and civic involvement in an urban industrial neighbourhood. Health \& Place 7 (3):163-177.

Watson, A., and K.E. Till. 2010. Ethnography and participant observation. The SAGE handbook of qualitative geography, 121-137

Williams, K. 2015. In Ohio's 'Chemical Valley,' a debate over good jobs and bad health. The Washington Post. https://www.washingtonpost.com/national/in-ohios-chemical-valley-adebate-over-good-jobs-and-bad-health/2015/12/12/3341b626-8fab-11e5-baf4bdf37355da0c story.html (last accessed 1 June 2021).

Wolf, E. 1972. Ownership and political ecology. Anthropological Quarterly 45: 201-05. 